\title{
Qrevisto
}

\section{AVALIAÇÃO \\ QUADRIENAL DA \\ CAPES: SENTENÇA OU \\ AUXÍLIO}

CAPES QUADRENNIAL EVALUATION: AWARD OR AID

EVALUACIÓN CUADRIENAL DE LA CAPES: SENTENCIA O AYUDA

\section{Alessandra Bonfim Bacelar de Abreu Adrian ${ }^{1}$ Francisco Gilson Rebouças Porto Junior ${ }^{2,3}$}

\section{RESUMO}

A região Norte do país sempre esteve em desvantagens quando o assunto é formação superior, os dados da CAPES revelam que o número de doutores e mestres ainda não são suficientes para suprir as demandas principalmente em se falando na oferta de novos programas de pós-graduação, onde são feitos verdadeiros malabarismos, juntando áreas afins para conseguir formar quadro de docentes. E se é difícil para os cursos de exatas, saúde, como será para humanas, mais especificamente, comunicação. Esse artigo mostra um panorama atual dos programas existentes na região norte do país, tendo como referência

\footnotetext{
1 Mestra em Comunicação e Sociedade pelo Programa de Pós-Graduação em Comunicação e Sociedade (PPGCom-UFT). Pedagoga e Jornalitas com especialização em Educação Comunicação e Novas Tecnologias, MBA em Gestão da Comunicação e Marketing. Funcionária pública. E-mail: alessandrabacelar@gmail.com.

2 Doutor em Comunicação e Cultura Contemporâneas pela Faculdade de Comunicação da Universidade Federal da Bahia (UFBA), mestre em Educação pela Faculdade de Educação (UnB) e graduado em Comunicação Social/Jornalismo (ULBRA) e Pedagogia (UnB). Atualmente é líder do Núcleo de Pesquisa e Extensão e Grupo Lattes Observatório de Pesquisas Aplicadas ao Jornalismo e ao Ensino (OPAJE-UFT). É professor na Fundação Universidade Federal do Tocantins (UFT). E-mail: gilsonporto@uft.edu.br.

${ }^{3}$ Endereço de contato dos autores (por correio): Universidade Federal do Tocantins (UFT). Mestrado em Comunicação e Sociedade (PPGCOM-UFT). Avenida NS 15, 109 Norte - Plano Diretor Norte - Palmas -TO, 77001-090 Brasil.
} 


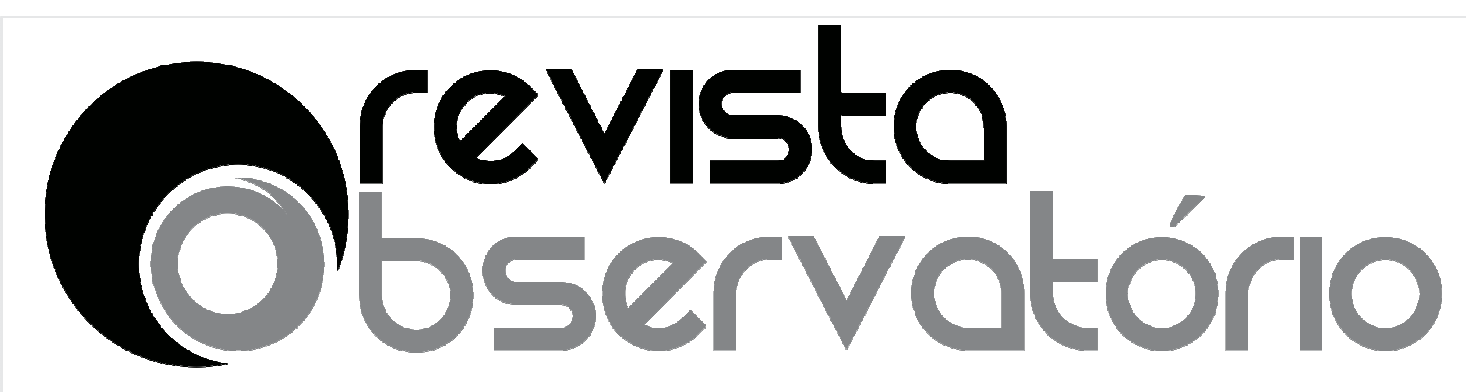

ISSN n² 2447-4266

Vol. 5, n. 3, Maio. 2019

DOI: http://dx.doi.org/10.20873/uft.2447-4266.2019v5n3p366

principal a Avaliação Quadrienal realizada junto as IES e registradas via Plataforma Sucupira e onde os últimos dados divulgados são do ano de 2017.

PALAVRAS-CHAVE: Formação; Comunicação, PPGCom; Avaliação Quadrienal; Região Norte.

\section{ABSTRACT}

The Northern region of the country has always been at a disadvantage when it comes to higher education, CAPES data show that the number of doctors and masters is still insufficient to meet the demands, mainly in terms of offering new ones graduate programs, where they are made real juggling, joining related areas to achieve a teaching staff. And if it is difficult for courses of exact, health, as will be for human, more specifically, communication. This article shows a current panorama of the existing programs in the northern region of the country, having as main reference the Quadrennial Evaluation carried out with the HEls and registered via the Platform Sucupira and where the latest data released are from the year 2017.

KEYWORDS: Formation; Communication, PPGCom; Quadrennial Evaluation; North region.

\section{RESUMEN}

La región Norte del país siempre estuvo en desventajas cuando el asunto es formación superior, los datos de la CAPES revelan que el número de doctores y maestros aún no son suficientes para suplir las demandas principalmente en hablar de la oferta de nuevos programas de postgrado, donde se hacen verdaderos malabarismos, juntando áreas afines para conseguir formar cuadro de docentes. Y si es difícil para los cursos de exacta, salud, como será para las personas, más específicamente, comunicación. Este artículo muestra un panorama actual de los programas existentes en la región norte del país, teniendo como referencia principal la Evaluación Quadrienal realizada junto a las IES y registradas vía Plataforma Sucupira y donde los últimos datos divulgados son del año 2017. 


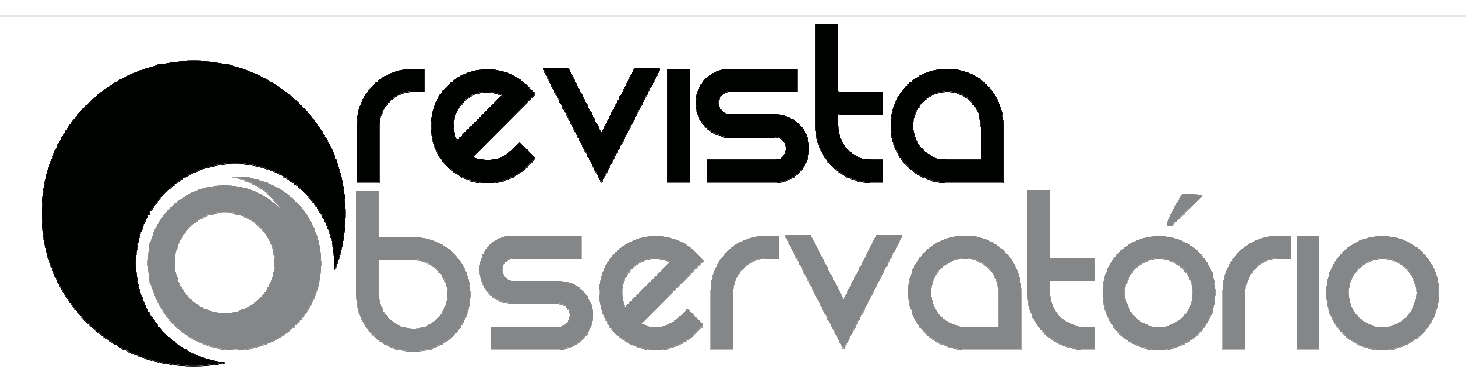

ISSN n² 2447-4266

Vol. 5, n. 3, Maio. 2019

DOI: http://dx.doi.org/10.20873/uft.2447-4266.2019v5n3p366

PALABRAS CLAVE: Formación; Comunicación, PPGCom; Evaluación cuatrienal; Región del norte.

Recebido em: 12.10.2018. Aceito em: 15.02.2019. Publicado em: 01.05.2019. 


\section{Crevisto \\ Observatório}

ISSN n² 2447-4266

Vol. 5, n. 3, Maio. 2019

DOI: http://dx.doi.org/10.20873/uft.2447-4266.2019v5n3p366

\section{Introdução}

Este artigo tem como objetivo principal refletir sobre os Processos e Políticas de Formação em cursos de mestrado em comunicação na região norte do Brasil, revelando caminhos de pesquisa realizada sobre o processo de formação a nível de Mestrado nos Programas ofertados nas Universidade Públicas, analisando como foram criados, as matrizes curriculares, corpo docente, produção acadêmica, inserção social entre outros aspectos tendo como pano de fundo os resultados finais da Avaliação Quadrienal realizada pela CAPES - Coordenação de Aperfeiçoamento de Pessoal de Nível Superior

Foi identificado inicialmente que três Instituições de Ensino Superior Pública ofertavam programas de pós-graduação em comunicação: UFAM Universidade Federal do Tocantins, UFPA - Universidade Federal do Pará e a UFT, sendo que a primeira havia sido descredenciada quando da última Avaliação Quadrienal (2017) por não atingir o conceito necessário para a oferta da formação, apesar dessa situação ela foi incluída nos estudos.

Iniciar a referida pesquisa sobre às Universidades e os processos de formação se deu após o estudo do denominado "Processo de Bolonha", durante o curso de especialização em Formação de Professores em Jornalismo/Comunicação em Temas Contemporâneos oferecido pela UFT, e também pela leitura de autores/pesquisadores que tem se debruçado a entender melhor essa nova dinâmica a exemplo de Pôrto (2015), Lima, Azevedo e Catani (2008), Silva (2013), Melo (2017).

Ali na sala de aula surgiu uma nova perspectiva de formação, que leva em conta a qualidade mas, além disso, a preocupação com a inserção no 


\section{Revisto \\ Observotório}

mercado e com o tempo dedicado à formação em tempo menor do que está proposto atualmente nos programas de mestrado e que acabam afastando muitas pessoas do caminho da academia, tendo em vista a necessidade de trabalho ser mais importante que a formação continuada, como bem aponta Lima (2008):

Em 1998, em Paris, os ministros da educação da Alemanha, França, Itália e Reino Unido assinaram uma declaração conjunta onde perspectivam já a construção de um "espaço europeu de educação superior" (DECLARAÇÃO DA SORBONNE, 1998). No ano seguinte, os ministros de vinte e nove estados europeus, incluindo Portugal, subscreveram a chamada Declaração de Bolonha (1999), onde assumem como objetivos o estabelecimento, até 2010, de um espaço europeu de educação superior coerente, compatível, competitivo e atrativo para estudantes europeus e de países terceiros. A construção do referido sistema europeu de educação superior é considerada "a chave para promover a mobilidade e a empregabilidade dos cidadãos" e para a "obtenção de maior compatibilidade e de maior comparabilidade". Embora se recuse a idéia de simples homogeneização ou padronização, eventualmente menos aceitável face à grande diversidade da educação superior dos países aderentes, insiste-se na harmonização e na necessidade da coordenação de políticas, na promoção da dimensão europeia dos currículos, na cooperação internacional, na mobilidade e no intercâmbio, bem como na cooperação no "setor da avaliação da qualidade, tendo em vista vir a desenvolver critérios e metodologias que sejam passíveis de comparação (DECLARAÇÃO DE BOLONHA, 1999). (LIMA et al. p. 10).

Essa busca por um processo mais rápido, o qual não afaste da empregabilidade aqueles que desejam retornar ao mundo acadêmico, é desmistificado pelo sociólogo Bauman (2001) que, em estudos e livros, entre eles o Modernidade Líquida, deixa claro que a sociedade líquida não pensa a longo prazo e, não conseguindo traduzir seus desejos em projetos de longa duração, perderam os grandes projetos e o alcance do objetivo não é mais a força da sociedade. Diante desse cenário de urgência, descrito pelo autor, se fez necessário pensar como estão estruturados os cursos de mestrado em Comunicação, pois eles são responsáveis pela formação dos professores que, 


\section{Qbevisto \\ ISSN n² 2447-4266 \\ Vol. 5, n. 3, Maio. 2019 \\ DOI: http://dx.doi.org/10.20873/uft.2447-4266.2019v5n3p366}

em sala de aula, vão conduzir os alunos do status de aprendizes para executores de tarefas.

Castells (1999) também traz à baila esse novo papel do trabalhador. Segundo ele, é preciso ter uma formação que seja capaz de dar suporte a qualquer atividade, saindo de cena o profissional especialista tão amplamente divulgado na Era Fordista e entrando um generalista que é capaz de migrar de uma atividade a outra para atender as demandas.

A partir dessas considerações, dois objetivos importantes que permearam a pesquisa. $\mathrm{O}$ primeiro deles, compreender como ocorreram os processos e políticas de formação nos cursos de mestrado em comunicação na região norte do Brasil, onde se pretendeu verificar mudanças ocasionadas pelo surgimento de novas perspectivas formativas e o impacto nas grades curriculares, gerando ou não transformações e ou adequações nos programas.

O segundo objetivo geral que norteou a pesquisa foi analisar como estão estruturadas as matrizes curriculares dos cursos de pós-graduação stricto sensu em comunicação. Observando a ocorrência de mudanças ao longo dos anos, quais foram essas mudanças, a partir de que pressupostos essas mudanças foram implantadas. Através da análise mais refinada das matrizes curriculares foi possível conhecer, na essência, o que se pretende nos cursos avaliados. Conhecendo a trajetória, os erros e os acertos, é possível entender as dificuldades encontradas/superadas e o impacto dessas transformações no processo de formação.

Por se tratar de memória viva e recente, os dados foram coletados a partir de pesquisa documental, tendo em vista que os documentos representam o registro da construção dos programas e se constituem enquanto fonte de pesquisa para os pesquisadores, pois ali está contida toda a riqueza de um recorte de vida. Nessa perspectiva, Cellard (2008, p. 295) indica que: 


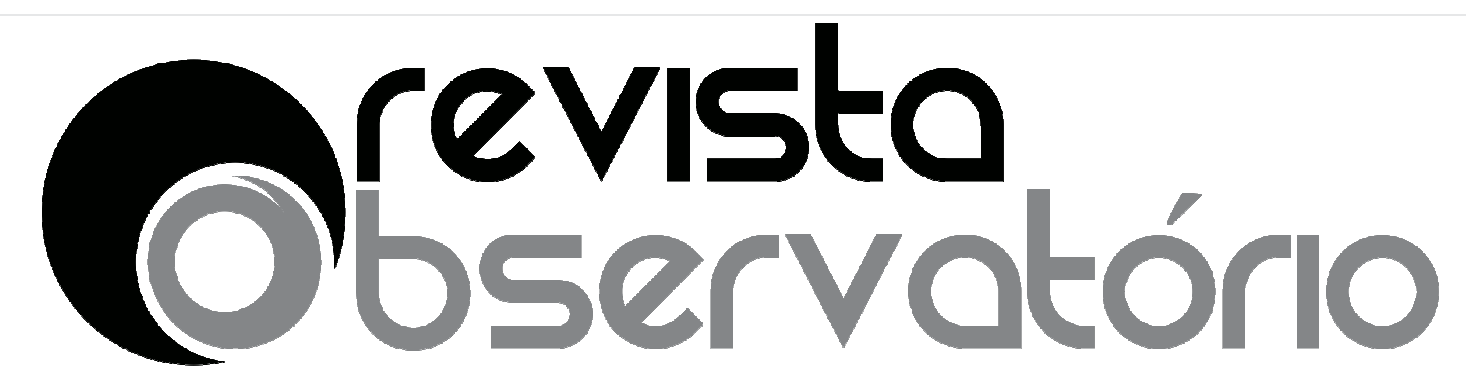

ISSN n² 2447-4266

Vol. 5, n. 3, Maio. 2019

DOI: http://dx.doi.org/10.20873/uft.2447-4266.2019v5n3p366

(...) o documento escrito constitui uma fonte extremamente preciosa para todo pesquisador nas ciências sociais. Ele é, evidentemente, insubstituível em qualquer reconstituição referente a um passado relativamente distante, pois não é raro que ele represente a quase totalidade dos vestígios da atividade humana em determinadas épocas. Além disso, muito frequentemente, ele permanece como o único testemunho de atividades particulares ocorridas num passado recente.

Também fez parte da metodologia a pesquisa bibliográfica e a leitura de autores, teses, dissertações, dentre outros, que auxiliaram uma melhor compreensão sobre o tema do trabalho, contribuindo para a elaboração da dissertação. Conforme destaca Lakatos (2003, p. 183):

A pesquisa bibliográfica, ou de fontes secundárias, abrange toda bibliografia já tornada pública em relação ao tema de estudo, desde publicações avulsas, boletins, jornais, revistas, livros, pesquisas, monografias, teses, material cartográfico etc., até meios de comunicação orais: rádio, gravações em fita magnética e audiovisuais: filmes e televisão. Sua finalidade é colocar o pesquisador em contato direto com tudo o que foi escrito, dito ou filmado sobre determinado assunto, inclusive conferências seguidas de debates que tenham sido transcritos por alguma forma, quer publicadas, quer gravadas.

\section{A Pós-Graduação Stricto Sensu no Brasil}

Alguns autores afirmam que a pós-graduação teria surgido com 0 advento do governo militar no país. Segundo Germano (2005) e Savianni (2008) a implementação teria começado por volta de 1968, como uma das estratégias de consolidação da Reforma Universitária, tendo a perspectiva da formação de quadros de alto nível, o surgimento da pesquisa e, ainda, o desenvolvimento das ciências, com foco nas novas tecnologias visando o desenvolvimento econômico do país. 


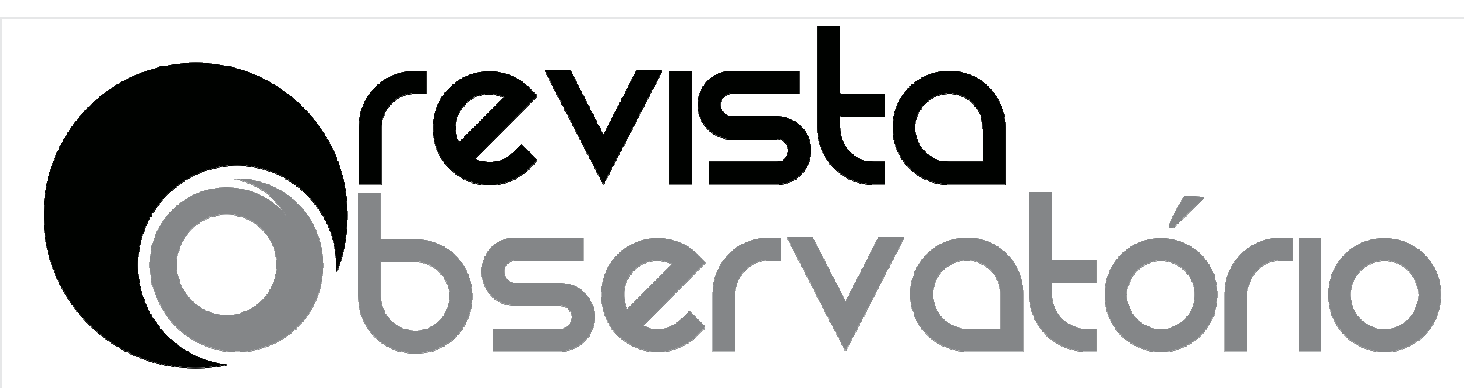

ISSN n² 2447-4266

Vol. 5, n. 3, Maio. 2019

DOI: http://dx.doi.org/10.20873/uft.2447-4266.2019v5n3p366

Outros autores defendem que esse surgimento teria ocorrido anos antes, ainda no início da década de 1930. De acordo com Balbachevsk (2004), neste período as primeiras universidades brasileiras atraíram professores estrangeiros e eles teriam trazido na bagagem o primeiro modelo institucional para os estudos na pós-graduação no Brasil.

A relação deste modelo envolvia um esquema tutorial entre um professor catedrático e um pequeno grupo de discípulos, que viriam a ser os futuros docentes dessas instituições. Inicialmente a pósgraduação se desenvolveu sem qualquer regulamentação externa. Em boa medida, mas não exclusivamente, era extensão da própria carreira docente. Em muitos casos, a defesa da dissertação ou da tese poderia demorar até mais de uma década, mercế das complexidades existentes naquela época. Este modelo pouco impactou na educação superior brasileira, já que se tratava de seletos e reclusos grupos encontrados em pouquíssimas universidades e fora delas seus títulos pouco valiam, mas a persistência desses pequenos grupos de pesquisadores foi um dos fatores que permitiram a formação das gerações futuras que fizeram surgir à pós-graduação no Brasil. (BALBACHEVSK, 2004, p. 3)

Pôrto Júnior (2001) relembra uma figura importante desse período, Anísio Teixeira, que teria participado ativamente na luta na escola pública primária, secundária e também na Universidade, inspirado nos anos de estudos fora do país e na admiração pelo pedagogo John Dewey. Teixeira foi o responsável pela existência da UDF - Universidade do Distrito Federal, criada em 1935 e extinta em 1938, resultado de perseguições. Mas o autor enfatiza que, antes da UDF, houve uma grande movimentação no país em torno da criação desse espaço que, segundo Teixeira, representava a formação profissional, o alargamento da mente humana, o desenvolvimento do saber humano e a transmissão de uma cultura comum. Segundo Pôrto Junior, poderia ser essa uma trajetória de luta pela Universidade no Brasil: 


\section{Revisto Observotório}

Em 1892, José Francisco da Rocha Pombo teve a ideia de fundar uma universidade na capital do Paraná, porém a ideia ficou apenas na pedra fundamental; ainda nesse ano, Pedro Américo apresentou em 29 de agosto na Câmara dos Deputados a criação de três universidades, sendo uma no Rio de Janeiro (DF), uma em São Paulo (SP) e uma no norte do Brasil (Bahia, Pernambuco ou Pará); em 1895, os deputados Eduardo Ramos e Paulino de Souza Filho apresentaram à Câmara dos Deputados, o projeto $n^{\circ} 91$ de criação de uma universidade na capital da República composta de quatro faculdades: direito, medicina, ciências naturais e matemáticas e de letras; em 1896, Francisco Glycerio apresentou projeto de lei transferindo a diferentes estados e associações civis os institutos de instrução superior para a administração estadual; em 1900, Elysio de Carvalho, tentou fundar a Universidade Popular; em 1903, Gastão da Cunha, através do projeto $n^{\circ} 157$, criou cinco universidades nas cidades do Rio de Janeiro, São Paulo, Bahia, Recife e de Belo Horizonte. Este projeto era de autoria do prof. Azevedo Sodré, catedrático da Faculdade de Medicina do Rio de Janeiro; em 1904, Rodrigues Lapa (Lima?) propôs através do projeto $\mathrm{n}^{\circ} 147$, a criação da Universidade do Rio de Janeiro, que seria constituída de quadro unidades (Faculdade de Direito, Faculdade de Medicina, Faculdade de Filosofia e Letras, Faculdade de Ciências Matemáticas, Físicas e Naturais); Ainda em 1904, o deputado Sátyro Dias apresentou aditivo ao projeto $n^{\circ}$ 157, de Azevedo Sodré, porém não teve andamento; em 1908 a câmara dos deputados aprovou o projeto $n^{\circ} 242$, de Virgílio Damásio, que autorizava uma reforma no ensino secundário e superior e que criava na cidade do Rio de Janeiro uma universidade pela justaposição das Faculdades de Direito, Medicina, Ciências e Letras e da Escola Politécnica (este projeto foi arquivado dois anos depois); ainda em 1908, Érico Marinho da Gama Coelho, professor da Faculdade de Medicina do Rio de Janeiro apresentou projeto que criava cinco Universidades em Pernambuco, Minas Gerais, Bahia, São Paulo e Rio de Janeiro, porém não teve andamento; em 1912, apoiando-se na Lei Rivadávia, fundou-se a Universidade do Paraná, com cinco faculdades (Direito, Engenharia, Odontologia, Farmácia e Comércio), que em 1915 foi fechada, sendo somente reaberta em 1946; em 1915 a Reforma Maximiliano autorizou a criação de uma Universidade, mas nenhuma providência foi tomada para implantá-la. Subitamente, em 1920, o decreto $\mathrm{n}^{\circ}$ 11.530, apresentado por Carlos Maximiliano Pereira dos Santos declarou instituída a Universidade do Rio de Janeiro, com a justaposição da Escola Politécnica à Faculdade de Medicina, e a incorporação concomitante das duas faculdades livres de Direito. (PÔRTO JÚNIOR, 2001, p. 47)

Santos (2003) também define essa data como o marco inicial. Segundo ele, "os primeiros passos da pós-graduação no Brasil foram dados no início da 


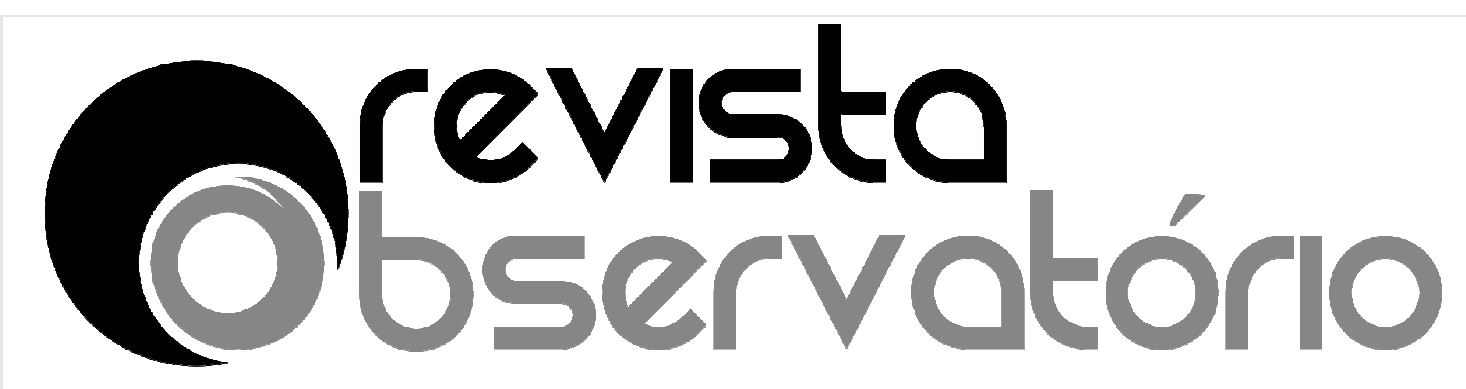

ISSN n² 2447-4266

Vol. 5, n. 3, Maio. 2019

DOI: http://dx.doi.org/10.20873/uft.2447-4266.2019v5n3p366

década de 1930, na proposta do Estatuto das Universidades Brasileiras, onde Francisco Campos propunha a implantação de uma pós-graduação nos moldes europeus" (2003, p. 2).

A criação da CAPES é o divisor de águas para a pós-graduação no Brasil, ela surge num contexto onde o país precisava sair do obsoletismo e entrar na era da competitividade, isso era enxergado, por muitos, como somente sendo possível por meio da implantação de uma política de desenvolvimento científico e tecnológico a ser instituída na política de pós-graduação, ainda não tão bem definidos no país.

Córdova (2003) faz uma reflexão sobre a situação da força de trabalho onde revela dados do censo de 1950, comparado ao de 1940, mostrando uma acentuada transferência da mão de obra para os setores secundário e terciário da economia e a migração da mão de obra excedente da região Norte para o Centro-Sul. Destaca, ainda, o contingente de profissionais de nível superior, um número tímido para o país que sonhava em ser potência, fixado em 0,67\% da massa da população economicamente ativa, o que representava, em valores absolutos, 132.035 profissionais em 1950, distribuídos da seguinte maneira:

[...] 111.902 (85\%) estavam na região Centro-Sul, 15.331 (12\%) na região Nordeste e 4.802 (3\%) na região Norte (o Centro-Oeste ainda não era especificamente considerado). Do ponto de vista dos grupos profissionais, 7.447 (6\%) eram agrônomos e veterinários, 25.532 (19\%) eram engenheiros e correlatos (químicos industriais e arquitetos), 54.255 (41\%) eram médicos, dentistas e farmacêuticos, e 44.801 (34\%) eram advogados, economistas e "conexos" (isto é, formados em Filosofia, Ciências, Letras e Pedagogia). Nessa época a relação entre o número de profissionais de nível superior e a população total era de 2.560 por milhão de habitantes, considerando-se o Brasil como um todo, mas apresentava acentuada diferenciação regional, de sorte que era de 3.701 por milhão na região Centro-Sul, de 936 no Nordeste e de 968 no Norte. (CÓRDOVA, 2003, p. 4) 


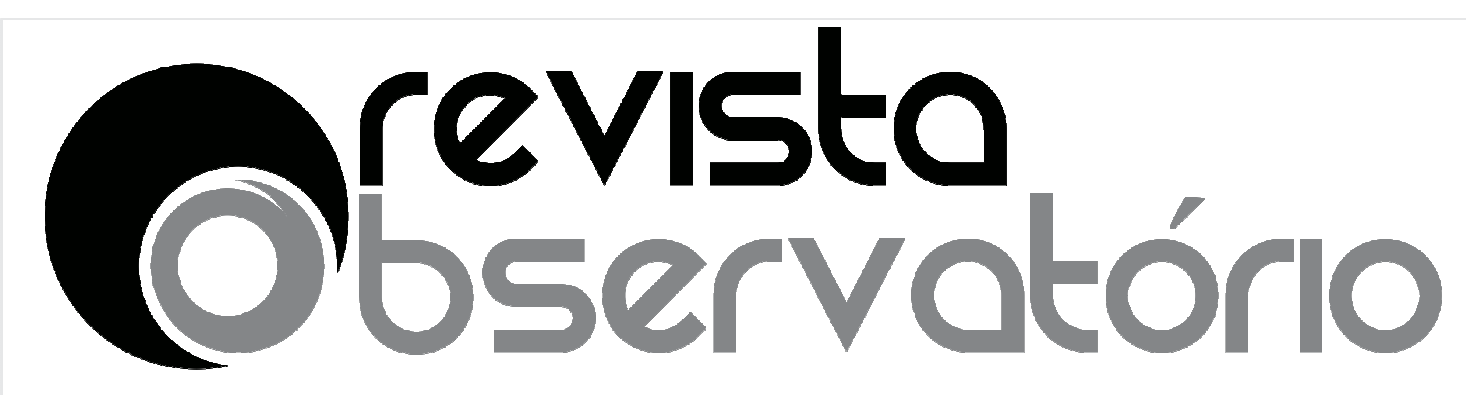

ISSN n² 2447-4266

Vol. 5, n. 3, Maio. 2019

DOI: http://dx.doi.org/10.20873/uft.2447-4266.2019v5n3p366

O autor ainda faz uma análise geral levando em consideração vários autores e conclui que o problema é generalizado na educação: desde a alfabetização ao ensino superior. Para este último, era preciso voltar um olhar mais dedicado e esse cenário se torna o maior contribuinte para a criação da CAPES.

Morosini e Souza (2009) indicam que é na normatização da universidade com a concepção de produção de conhecimento/pesquisa indissociável do ensino e com apoio de um modelo humboldtiano, que surge, com a reforma universitária de 1968 - Lei n 5.540 -, um modelo que tem forte inspiração no modelo norte-americano, com a implantação de departamentos universitários. As autoras identificam os títulos de mestrado e doutorado como sendo prérequisitos ao ingresso na carreira de professor universitário e que, com essa reforma, o modelo de Instituição de Ensino Superior passa a ser a universidade, produtora de conhecimento por intermédio da pesquisa.

De acordo com Velloso (2002), quando a pós-graduação brasileira foi regulamentada, existia em todo o país 38 cursos, sendo onze de doutorado e vinte e sete de mestrado sendo estes últimos distribuídos nas áreas de Ciências Humanas, Ciências Sociais Aplicadas, além das Ciências Agrárias e das Engenharias. Porém, Santos e Azevedo (2009) "destacam que não havia uma definição clara dos fins e objetivos da pós-graduação, nem da sua estrutura e, para as autoras, teria sido esse um dos motivos que levaram à elaboração do Parecer 977/65 "tendo em vista a necessidade de implantar e desenvolver no ensino superior a pós-graduação, cuja definição e regulamentação viriam superar a "imprecisão que reina[va] entre nós sobre a natureza desses cursos" (Brasil, 1965). 


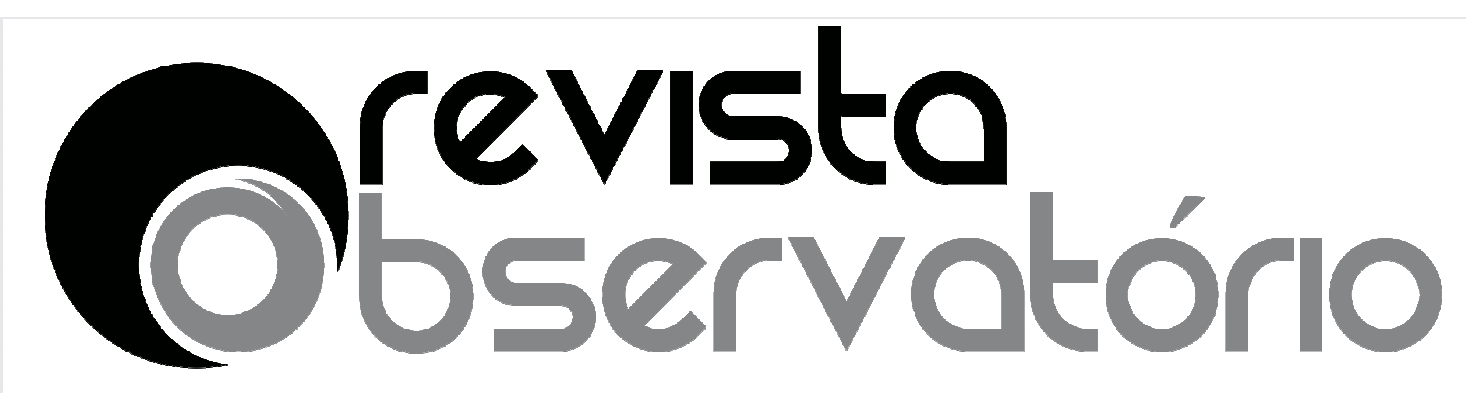

ISSN n² 2447-4266

Vol. 5, n. 3, Maio. 2019

DOI: http://dx.doi.org/10.20873/uft.2447-4266.2019v5n3p366

\section{O papel da CAPES na consolidação da Pós-Graduação}

De acordo com Córdova (2003), a CAPES é uma organização ligada umbilicalmente à história da pós-graduação no Brasil, ainda que existam outras instituições envolvidas, tendo em Anísio Teixeira seu principal entusiasta e implantando programas, concedendo bolsas, promovendo intercâmbios e cooperações no intuito claro de fortalecer a instituição.

Consta no site da CAPES - com publicação em 11 de maio de 2012 e última atualização em 08 de novembro de 2017 - que são quatro as Iniciativas Institucionais: Plano Nacional de Pós-Graduação, Plano de Dados Abertos, Plano de Integração ao Portal de Serviços à Plataforma de Cidadania Digital e o Plano Diretor de Tecnologia da Informação. Já as Iniciativas por Área Finalística estão distribuídas da seguinte forma (CAPES, 2017):

- $\quad$ Avaliação da pós-graduação stricto sensu:

Avaliação dos Programas de Pós-Graduação

Plataforma Sucupira

- Acesso e divulgação da produção científica:

Portal de Periódicos

- Investimentos na formação de recursos de alto nível no país e exterior:

Bolsas de Pós-Graduação no Exterior Bolsas de Pós-Graduação no País

- Promoção da cooperação científica internacional:

Cooperação Internacional

- Indução e fomento da formação inicial e continuada de professores para a educação básica nos formatos presencial e a distância: 


\section{Revisto \\ Observatório \\ ISSN n $2447-4266$ \\ Vol. 5, n. 3, Maio. 2019 \\ DOI: http://dx.doi.org/10.20873/uft.2447-4266.2019v5n3p366 \\ Formação de Professores da Educação Básica \\ Educação a Distância \\ Educapes \\ Britannica Escola}

Ainda tendo como base as informações do site institucional da CAPES, a Avaliação do Sistema Nacional de Pós-Graduação, na forma como foi estabelecida a partir de 1998, é atividade essencial para assegurar e manter a qualidade dos cursos de Mestrado e Doutorado no país e tem como objetivos: Certificação da qualidade da pós-graduação Brasileira (referência para a distribuição de bolsas e recursos para o fomento à pesquisa) e a Identificação de assimetrias regionais e de áreas estratégicas do conhecimento no SNPG para orientar ações de indução na criação e expansão de programas de pósgraduação no território nacional.

Morosini e Souza (2009) explicam que o Sistema de Avaliação para a PósGraduação atua na entrada e manutenção dos programas no sistema, compreendendo a realização de acompanhamento anual e a avaliação trienal do desempenho de todos os cursos integrantes do Sistema Nacional de PósGraduação - SNPG, onde os resultados da Avaliação são expressos pela atribuição de nota em escala de " 1 a 7" e têm como norteador o Conselho Nacional de Educação - CNE/MEC para a indicação de quais programas vão receber a renovação de reconhecimento para poder vigorar no triênio subsequente. As autoras se utilizam de levantamento de Jorge Guimarães, intitulado "O modelo brasileiro de formação de cientistas", apresentado no XXIV Encontro Nacional de Pró-Reitores de Pesquisa e Pós-Graduação, em 2008, para demonstrar a situação da avaliação realizada em 2007 sobre os programas avaliados onde, de um total de 2256 programas temos: nota 1 - 3 programas 


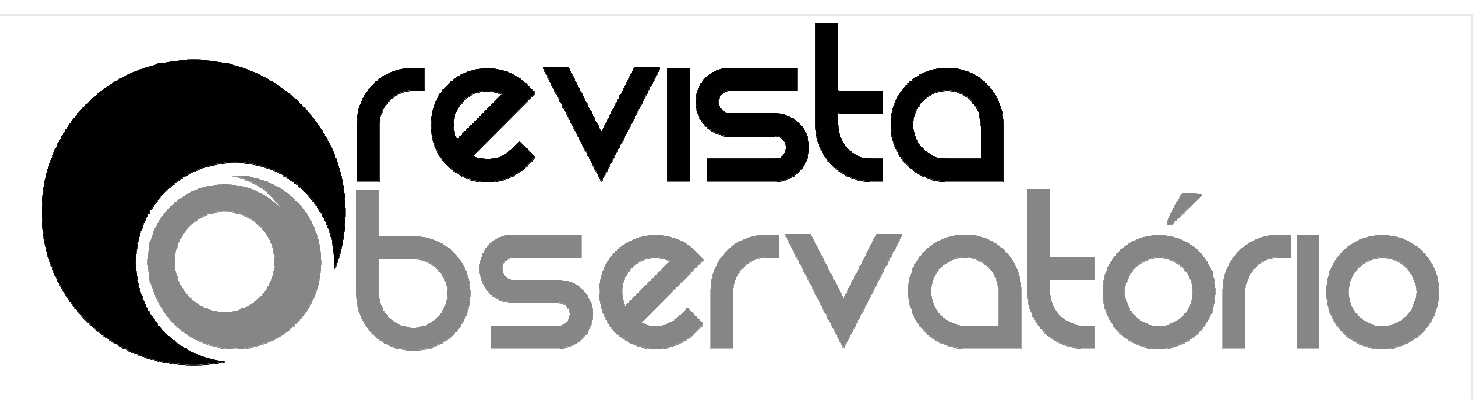

ISSN n² 2447-4266

Vol. 5, n. 3, Maio. 2019

DOI: http://dx.doi.org/10.20873/uft.2447-4266.2019v5n3p366

(0\%); nota $2-36(1 \%) ;$ nota $3-682(30 \%)$; nota $4-788(34 \%)$; nota $5-510$ (22\%); nota $6-155(6 \%)$; nota $7-82(3 \%)$ :

Tabela 1 - Programas de Pós-Graduação segundo notas e região, Brasil $-2007$

\begin{tabular}{|l|c|c|c|c|c|c|c|c|c|}
\hline Região & Programas & $\mathbf{1}$ & $\mathbf{2}$ & $\mathbf{3}$ & $\mathbf{4}$ & $\mathbf{5}$ & $\mathbf{6}$ & $\mathbf{7}$ & Média \\
\hline Sudeste & 1.177 & 2 & 17 & 280 & 370 & 323 & 115 & 70 & 4.3 \\
\hline Sul & 449 & - & 5 & 129 & 182 & 101 & 22 & 10 & 4.0 \\
\hline $\begin{array}{l}\text { Centro- } \\
\text { Oeste }\end{array}$ & 153 & 1 & 3 & 57 & 62 & 24 & 5 & 1 & 3.8 \\
\hline Nordeste & 384 & - & 9 & 159 & 146 & 57 & 12 & 1 & 3.7 \\
\hline Norte & 93 & - & 2 & 57 & 28 & 5 & 1 & - & 3.4 \\
\hline TOTAL & $\mathbf{2 . 2 5 6}$ & $\mathbf{3}$ & $\mathbf{3 6}$ & $\mathbf{6 8 2}$ & $\mathbf{7 8 3}$ & $\mathbf{5 1 0}$ & $\mathbf{1 5 5}$ & $\mathbf{8 2}$ & $\mathbf{4 . 1}$ \\
\hline
\end{tabular}

Fonte: Guimarães, 2008, apud Morosini e Souza (2009, p. 17)

O Sistema de Avaliação, segundo CAPES (2017), é dividido em dois:

Figura 1 - Divisão do Sistema de Avaliação da CAPES

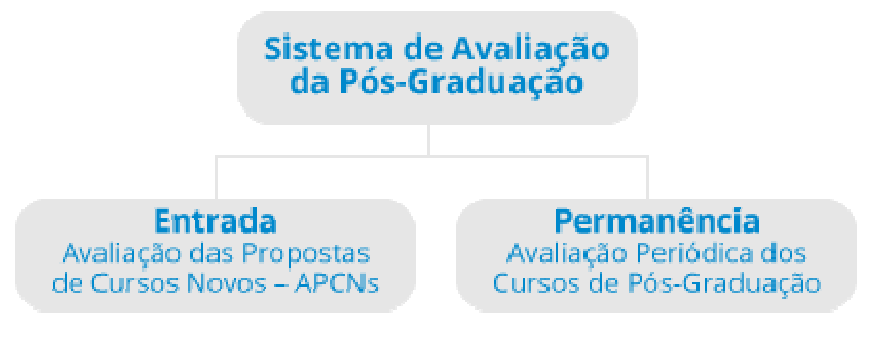

Fonte: Portal da CAPES (2017)

Esses dois processos se referem à entrada e permanência dos cursos de mestrado profissional (MP), mestrado acadêmico (ME) e doutorado (DO) no SNPG. Ambos os processos são conduzidos com base nos mesmos fundamentos: reconhecimento e Confiabilidade fundados na qualidade 


\section{Crevisto \\ Observatório}

DOI: http://dx.doi.org/10.20873/uft.2447-4266.2019v5n3p366

assegurada pela análise dos pares, critérios debatidos e atualizados pela comunidade acadêmico-científica a cada período avaliativo e Transparência firmada na ampla divulgação das decisões, ações e resultados no portal da CAPES e nas páginas das áreas de avaliação.

A Avaliação Trienal, parte do processo de permanência, e é realizada em 48 áreas de avaliação, seguindo sistemática e conjunto de quesitos básicos estabelecidos no Conselho Técnico Científico da Educação Superior (CTC-ES), seguindo o seguinte fluxo:

Figura 2 - Fluxo de Avaliação Trienal da CAPES

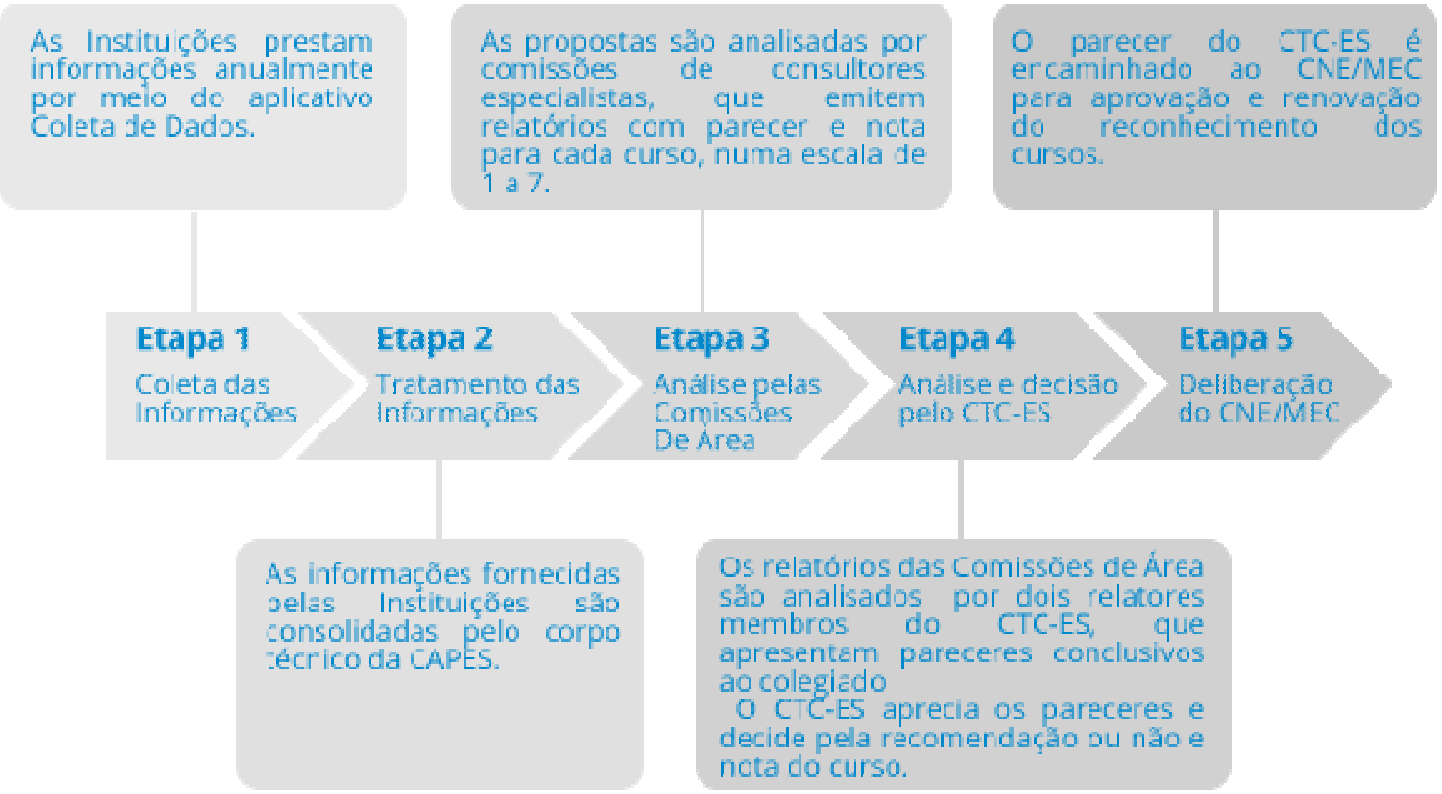

Fonte: Portal da CAPES (2017)

Os resultados da avaliação periódica de programas de pós-graduação são expressos em notas, numa escala de 1 a 7, que são atribuídas aos mestrados e doutorados após análise dos indicadores referentes ao período avaliado. Esta análise é conduzida nas comissões de área de avaliação e, 


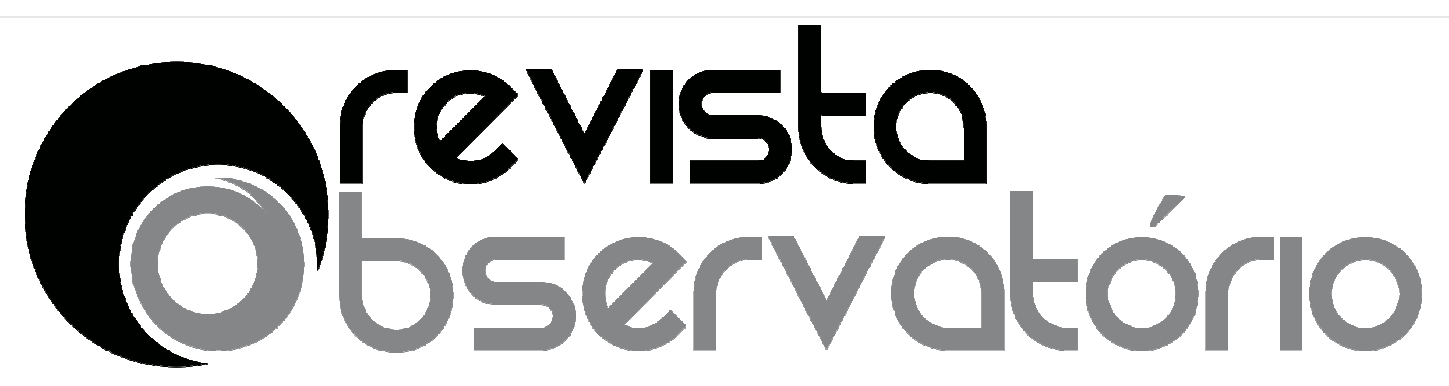

ISSN n² 2447-4266

Vol. 5, n. 3, Maio. 2019

DOI: http://dx.doi.org/10.20873/uft.2447-4266.2019v5n3p366

posteriormente, no CTC-ES, que homologa os resultados finais. São estes resultados que fundamentam a deliberação do Conselho Nacional de Educação - CNE/MEC sobre quais cursos obterão a renovação de reconhecimento para a continuidade de funcionamento no período subsequente.

A Avaliação Trienal de 2013, divulgada em 24 de abril de 2014 divulgada pela Diretoria de Avaliação aparecem os seguintes resultados:

Figura 3 - Avaliação Trienal de 2013
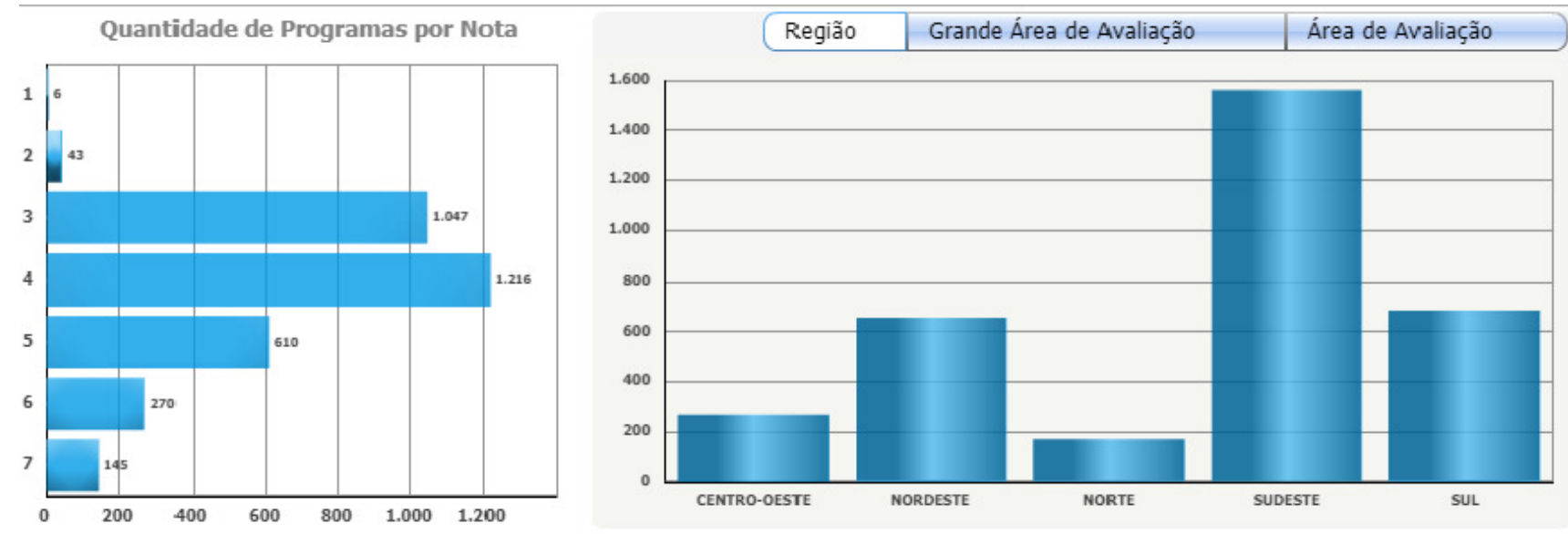

Fonte: Portal da CAPES, novembro de 2017.

O gráfico revela que a maior parte dos programas está localizada na região Sudeste: 1560. Em seguida, quase empatadas, estão a região Sul com684 e a região Nordeste com 655. A região Norte figura em último com 170.

Em relação às notas, que figuram de 1 a 7 , as maiores concentrações estão entre as 4 , 3 e 5 com 1.216, 1.047 e 610 respectivamente, como fica melhor demonstrando na tabela abaixo: 


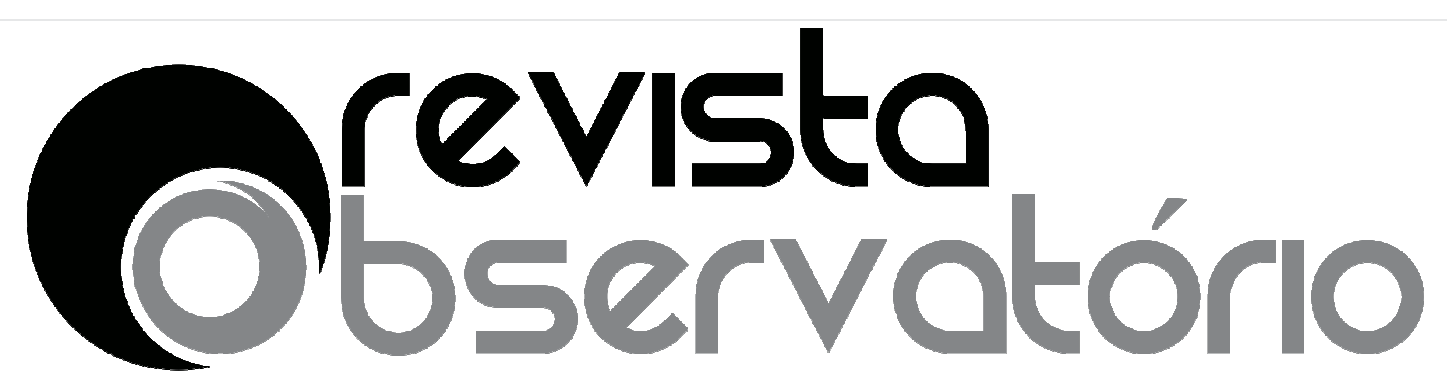

ISSN n² 2447-4266

Vol. 5, n. 3, Maio. 2019

DOI: http://dx.doi.org/10.20873/uft.2447-4266.2019v5n3p366

Tabela 2 - Variação das notas dos PPG's avaliados na Trienal 2013 em comparação à Trienal 2010

\begin{tabular}{|c|c|c|c|c|c|c|c|c|}
\hline $\begin{array}{l}\text { Nota } \\
\text { Atual } \\
(2013)\end{array}$ & 1 & 2 & 3 & 4 & 5 & 6 & 7 & Total \\
\hline $\begin{array}{l}\text { Nota } \\
\text { Anterior } \\
\text { (2010) }\end{array}$ & Qtd PPG's & Qtd PPG's & Qtd PPG's & Qtd PPG's & Qtd PPG's & Qtd PPG's & Qtd PPG's & $\begin{array}{c}\text { Qtd } \\
\text { PPG's }\end{array}$ \\
\hline 3 & 3 & 40 & 980 & 371 & 1 & & & 1.395 \\
\hline 4 & 2 & & 66 & 753 & 229 & 2 & & 1.052 \\
\hline 5 & & 2 & 1 & 89 & 352 & 126 & & 570 \\
\hline 6 & & & & 3 & 27 & 128 & 46 & 204 \\
\hline 7 & 1 & 1 & & & 1 & 14 & 99 & 116 \\
\hline Total & 6 & 43 & 1.047 & 1.216 & 610 & 270 & 145 & 3.337 \\
\hline
\end{tabular}

Fonte: Portal da CAPES, novembro de 2017

Em 2017 houve alteração no período de Avaliação, que passou a adotar o intervalo de quatro anos entre as análises, mudança provocada em decorrência da aceleração do crescimento do sistema nacional de pós-graduação 4 .

A Avaliação Quadrienal nos traz números e dados significativos que nos ajudam a situar o momento atual da Pós-Graduação no Brasil, tendo em vista que a análise feita pelas comissões de área de avaliação ocorreu bem recentemente, entre o período que compreende 03 de julho a 11 de agosto de 2017 e, posteriormente, os programas foram analisados pelo Conselho TécnicoCientífico no período compreendido entre 21 de agosto a 01 de setembro de 2017. No total, os consultores avaliaram 4.175 programas e seus 6.303 cursos, sendo 3.398 de mestrado, 2.202 de doutorado e 703 de mestrado profissional.

\footnotetext{
${ }^{4}$ Informação coletada de matéria publicada no site da CAPES, no dia 19 de setembro de 2017, e alterada no dia seguinte, a informação pode ser consultada no endereço: http://www.capes.gov.br/sala-de-imprensa/noticias/8558-avaliacao-da-capes-apontacrescimento-da-pos-graduacao-brasileira e acessada no dia 15/11/2017.
} 


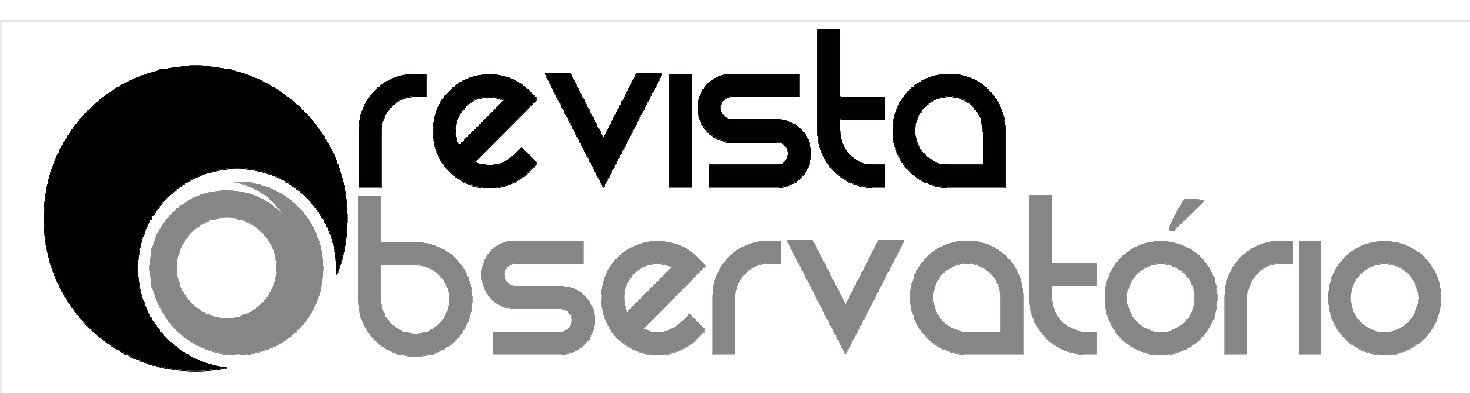

ISSN n² 2447-4266

Vol. 5, n. 3, Maio. 2019

DOI: http://dx.doi.org/10.20873/uft.2447-4266.2019v5n3p366

Os dados da CAPES demonstram que, em se falando de dados absolutos, o Sistema Nacional de Pós-Graduação avançou de 3.337 para 4.175 programas levando em consideração os números de 2013 a 2016, sendo que o maior crescimento observado foi nos cursos de mestrado profissional, em volta de $77 \%$, seguidos por uma elevação de $17 \%$ e $23 \%$ para o mestrado acadêmico e o doutorado respectivamente, como bem ilustra o gráfico abaixo:

Figura 4 - Gráfico do Crescimento dos cursos de pós-graduação

Crescimento dos cursos de pós-graduação

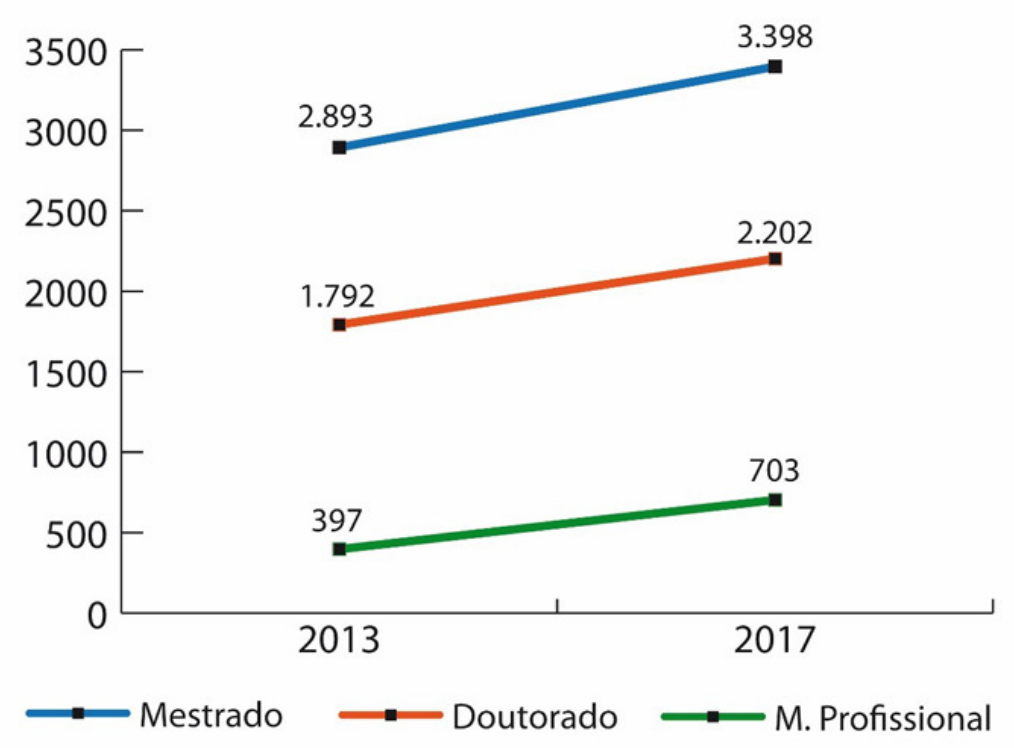

Fonte: CAPES, novembro de 2017

A CAPES (2017) também divulgou que atualmente o Brasil possui $11 \%$ dos programas com desempenho equivalente aos padrões internacionais de excelência, conseguindo obter as maiores notas - 6 e 7 - em o equivalente a 465 programas. A nota 5 compreende $18 \%$ e equivale ao nível de excelência 


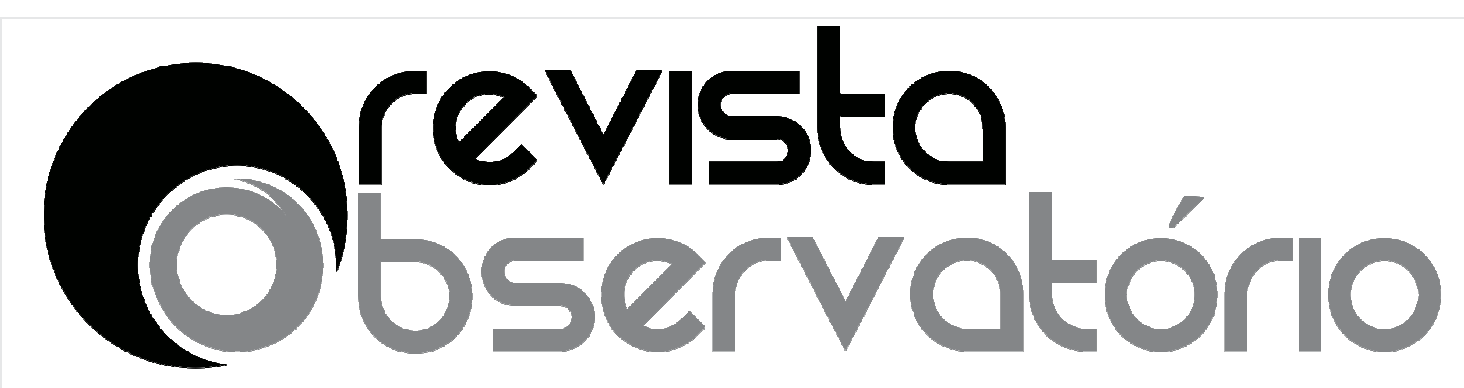

ISSN n² 2447-4266

Vol. 5, n. 3, Maio. 2019

DOI: http://dx.doi.org/10.20873/uft.2447-4266.2019v5n3p366

nacional e, juntamente com a 4 - que alcançou 35,33\% -, significam um desempenho entre bom e muito bom. Aos cursos que apresentam padrões mínimos de qualidade, programas abertos recentes que não formaram turmas e participam pela primeira vez, é dada a nota 3 .

Figura 5 - Distribuição de notas dos programas de pós-graduação

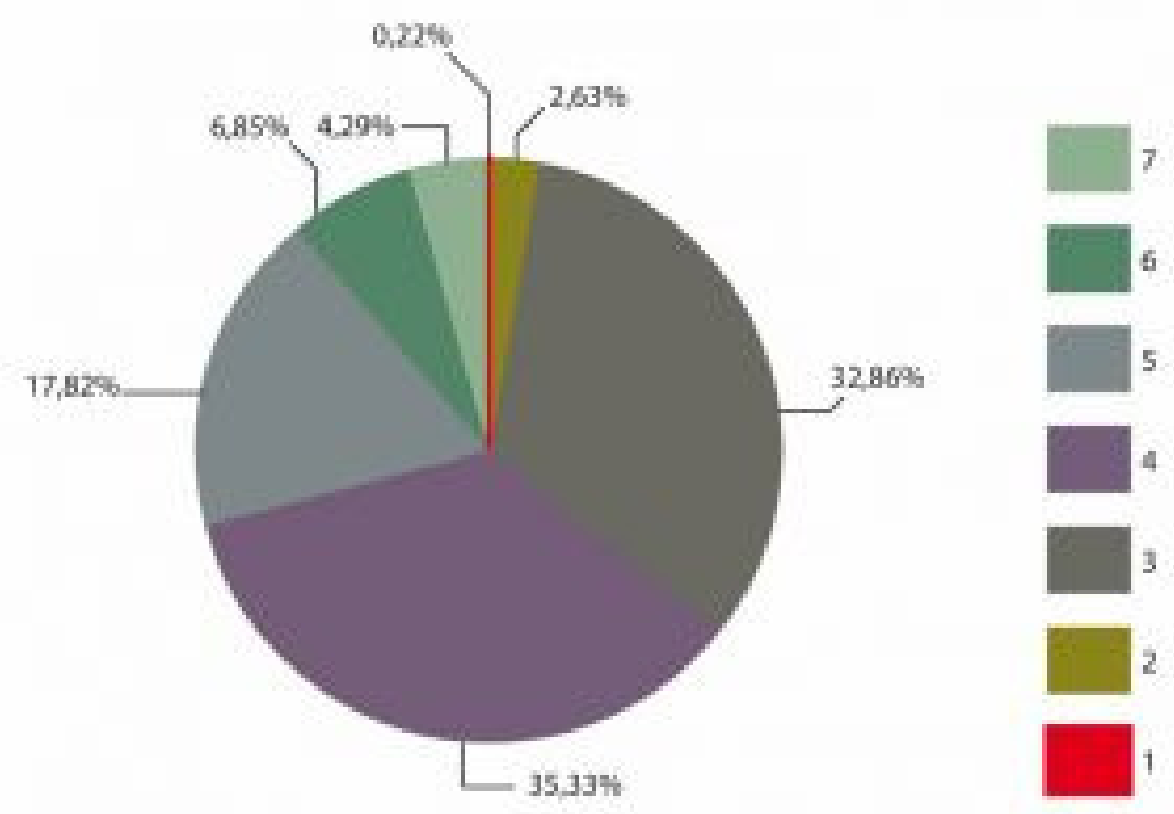

Fonte: CAPES, novembro de 2017

Finalizando o tópico sobre a CAPES, é importante considerar o recorte com foco na região Norte do país, área onde estão inseridos os programas a serem analisados nesta pesquisa. Segundo a Coordenação, na Avaliação realizada agora em 2017, verificou-se um bom desempenho da região Norte, além disso, tal região se destacou pela maior proporção de notas mantidas e uma maior concentração de programas nota 03 , por serem novos, no total 


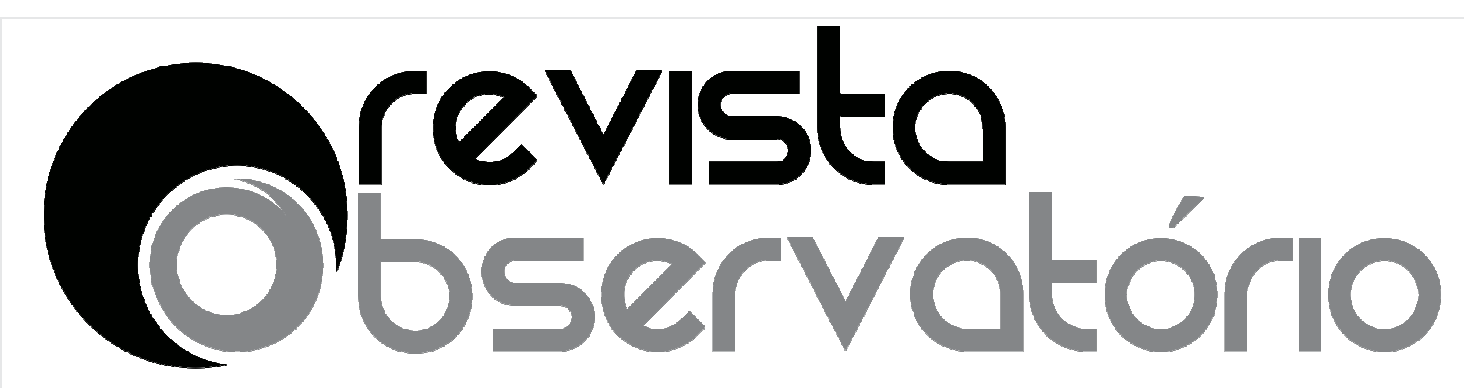

ISSN n² 2447-4266

Vol. 5, n. 3, Maio. 2019

DOI: http://dx.doi.org/10.20873/uft.2447-4266.2019v5n3p366

foram 113 programas avaliados com a nota 3 e, com a nota 4, foram 72 . Destaque para cinco programas de excelência nacional com nota 6. São eles: o programa de Ecologia do Instituto Nacional de Pesquisas da Amazônia (INPA) em Manaus, e os programas de Geologia e Geoquímica, Genética e Biologia Molecular, Biologia de Agentes Infecciosos e Parasitários e Desenvolvimento sustentável do Trópico Úmido da Universidade Federal do Pará em Belém.

A CAPES reconhece que na região Norte a pós-graduação teve um início relativamente tardio, por esse motivo, talvez, que nela estejam localizados somente $5 \%$ dos programas brasileiros, perfazendo um total de 227 , sendo que mais da metade implantados no Estado do Pará. A coleta de informação apurou que $15 \%$ dos programas existentes melhoraram as notas. Córdova (2003), em seus estudos sobre a CAPES, no que trata sobre a formação de mão de obra, mostra o seguinte panorama do Brasil e da região Norte do país:

[...] O censo de 1950 revelava, comparado com o de 1940, uma acentuada transferência da mão de obra para os setores secundário e terciário da economia, e uma migração da mão de obra excedente do Nordeste para o Centro-Sul, onde havia forte incremento das oportunidades de trabalho. O contingente de profissionais de nível superior correspondia a $0,67 \%$ da massa da população economicamente ativa. Em valores absolutos, estes profissionais somavam 132.035 em 1950, sendo que 111.902 (85\%) estavam na região Centro-Sul, 15.331 (12\%) na região Nordeste e 4.802 (3\%) na região Norte (o Centro-Oeste ainda não era especificamente considerado). Do ponto de vista dos grupos profissionais, 7.447 (6\%) eram agrônomos e veterinários, 25.532 (19\%) eram engenheiros e correlatos (químicos industriais e arquitetos), 54.255 (41\%) eram médicos, dentistas e farmacêuticos, e 44.801 (34\%) eram advogados, economistas e "conexos" (isto é, formados em Filosofia, Ciências, Letras e Pedagogia). Nessa época a relação entre o número de profissionais de nível superior e a população total era de 2.560 por milhão de habitantes, considerando-se o Brasil como um todo, mas apresentava acentuada diferenciação regional, de sorte que era de 3.701 por milhão na região Centro-Sul, de 936 no Nordeste e de 968 no Norte. $(2003$, p. 4$)$ 


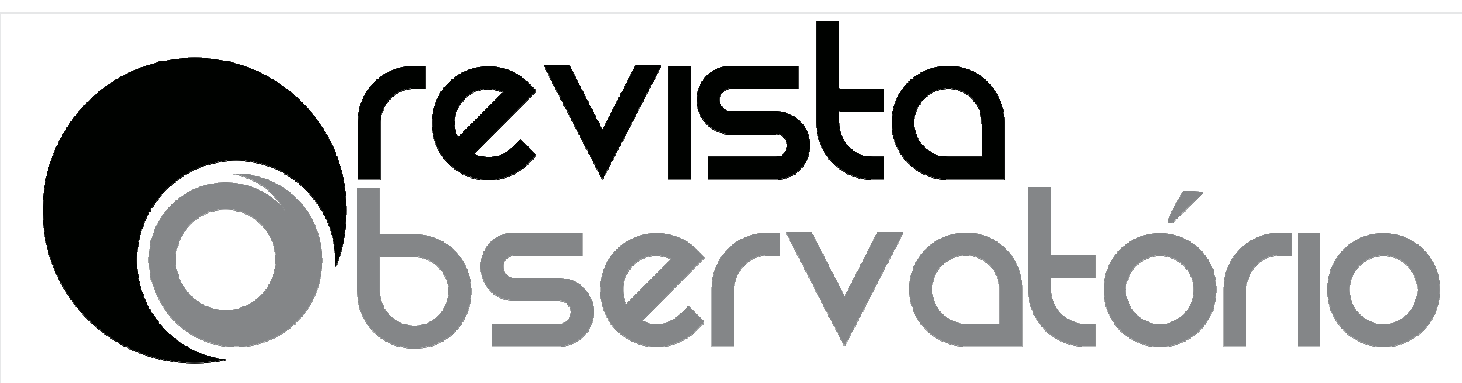

ISSN n² 2447-4266

Vol. 5, n. 3, Maio. 2019

DOI: http://dx.doi.org/10.20873/uft.2447-4266.2019v5n3p366

As informações demonstram que, desde o surgimento da pósgraduação no Brasil, a região Norte obteve pouca atenção e isso ocorreu em momentos históricos que exigiram, em determinados momentos, a necessidade de profissionais especializados os quais as empresas tratavam logo de buscar em outros centros. A Plataforma Sucupira traz, em seus últimos dados, oficiais uma tabela apresentando a situação da Região Norte:

Figura 6 - Distribuição da pós-graduação no Brasil

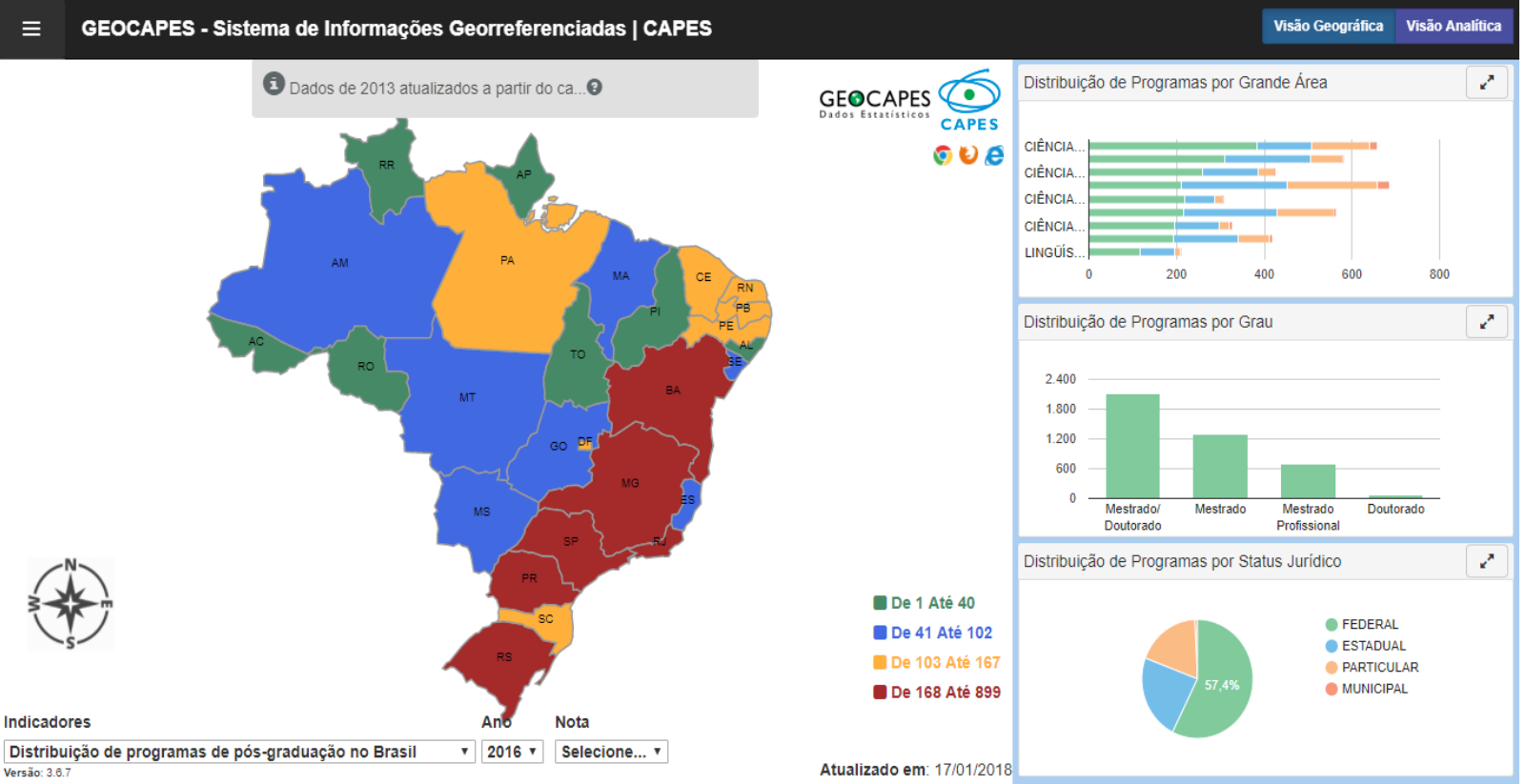

Fonte: Plataforma Sucupira - 04 de fevereiro de 2018

Os sete Estados da região norte possuem, no total, 328 programas de mestrado (acadêmico e profissional), doutorado e mestrado/doutorado, sendo 13 no Acre, 83 no amazonas, 8 no Amapá, 159 no Pará, 19 em Rondônia, 16 em Roraima e 30 no Tocantins. 


\section{Crevisto \\ Observatório}

ISSN n² 2447-4266

Vol. 5, n. 3, Maio. 2019

DOI: http://dx.doi.org/10.20873/uft.2447-4266.2019v5n3p366

Tabela 3 - Programas de pós-graduação da região Norte

\begin{tabular}{|c|c|c|c|c|c|c|c|c|c|c|}
\hline \multirow[b]{2}{*}{ UF } & & \multicolumn{5}{|c|}{ Total de Programas de pós-graduaçäo } & \multicolumn{4}{|c|}{ Totais de Cursos de pós-graduaçäo } \\
\hline & & Total & ME & DO & MP & MEIDO & Total & ME & DO & MP \\
\hline AM & & 62 & 31 & 1 & 9 & 21 & 83 & 52 & 22 & 9 \\
\hline PA & & 115 & 44 & 3 & 25 & 43 & 159 & 88 & 46 & 25 \\
\hline RO & & 15 & 8 & 0 & 4 & 3 & 19 & 11 & 3 & 5 \\
\hline RR & & 14 & 9 & 0 & 3 & 2 & 16 & 11 & 2 & 3 \\
\hline
\end{tabular}

ME: Mestrado Acadêmico

DO: Doutorado

MP: Mestrado Profissional

ME/DO: Mestrado e Doutorado

Fonte: Plataforma Sucupira / Portal da CAPES, novembro de 2017

\section{Os programas de mestrado e Avaliação Quadrienal da CAPES}

A Avaliação Quadrienal das Universidades feita pela CAPES obedece a Portaria nº 59 publicada no Diário Oficial da União do dia 27 de março de 2017. Os resultados do processo avaliatório dos Programas de Pós-Graduação stricto sensu devem permitir a consecução dos seguintes objetivos:

a) contribuir para a garantia da qualidade da pós-graduação brasileira que se efetiva na identificação dos programas que atendam ao padrão mínimo de qualidade exigido para cada nível de curso e que, em decorrência, terão a renovação de seu reconhecimento recomendada pela CAPES ao Conselho Nacional de Educação- CNE/MEC.

b) retratar a situação da pós-graduação brasileira no quadriênio de forma clara e efetiva, ao especificar: i. o grau diferencial de desenvolvimento alcançado pela pós-graduação nas diversas áreas do conhecimento; i.i. a classificação dos programas no âmbito de suas respectivas áreas, expressando as diferenças quanto à qualidade de desempenho na formação de recursos humanos e produção de 


\section{Crevisto}

Vol. 5, n. 3, Maio. 2019

DOI: http://dx.doi.org/10.20873/uft.2447-4266.2019v5n3p366

conhecimento a ela associada; iii. a caracterização da situação específica de cada programa, mediante a apresentação de relatório detalhado sobre seu desempenho no quadriênio 2013-2016.

c) contribuir para o desenvolvimento de cada programa e área em particular e da pós-graduação brasileira em geral ao fornecer, a cada programa avaliado, as apreciações criteriosas sobre os pontos fortes e os pontos fracos de seu desempenho, no contexto do conjunto dos programas da área, e antepor-lhes desafios e metas para o futuro. d) fornecer subsídios para a definição de planos e programas de desenvolvimento e a realização de investimentos no Sistema Nacional de Pós-Graduação- SNPG. (Site CAPES)

As avaliações foram realizadas por professores pertencentes a Universidades de vários Estados do país, num total de vinte e cinco docentes, e se limitou às Universidades definidas para a pesquisa: Universidade Federal do Tocantins, Universidade Federal do Pará e Universidade Federal do Amazonas. A mesma teve como base as fichas de Avaliação emitidas pela CAPES após análise dos dados cadastrados na plataforma Sucupira e que estão descritas nas tabelas abaixo. Os itens avaliados recebem notas que variam de Insuficiente a Muito Bom e o somatório delas vai determinar o conceito final, determinando se o Programa continuará ou não credenciado.

Tabela 4 - Ficha de Avaliação referente ao quesito Proposta de Programa

\begin{tabular}{|c|c|c|}
\hline \multicolumn{3}{|l|}{1 - Proposta de Programa } \\
\hline Itens de Avaliação & eso & $P$ \\
\hline $\begin{array}{l}\text { 1.1. Coerência, consistência, abrangência e atualização das áreas de } \\
\text { concentração, linhas de pesquisa, projetos em andamento e proposta } \\
\text { curricular. }\end{array}$ & 0.0 & 4 \\
\hline $\begin{array}{l}\text { 1.2. Planejamento do programa com vistas a seu desenvolvimento } \\
\text { futuro, contemplando os desafios internacionais da área na produção do }\end{array}$ & & \\
\hline
\end{tabular}




\section{revisto Observatório}

ISSN n² $2447-4266$

Vol. 5, n. 3, Maio. 2019

DOI: http://dx.doi.org/10.20873/uft.2447-4266.2019v5n3p366

conhecimento, seus propósitos na melhor formação de seus alunos, suas metas quanto a inserção social mais rica dos seus egressos, conforme os parâmetros da área.

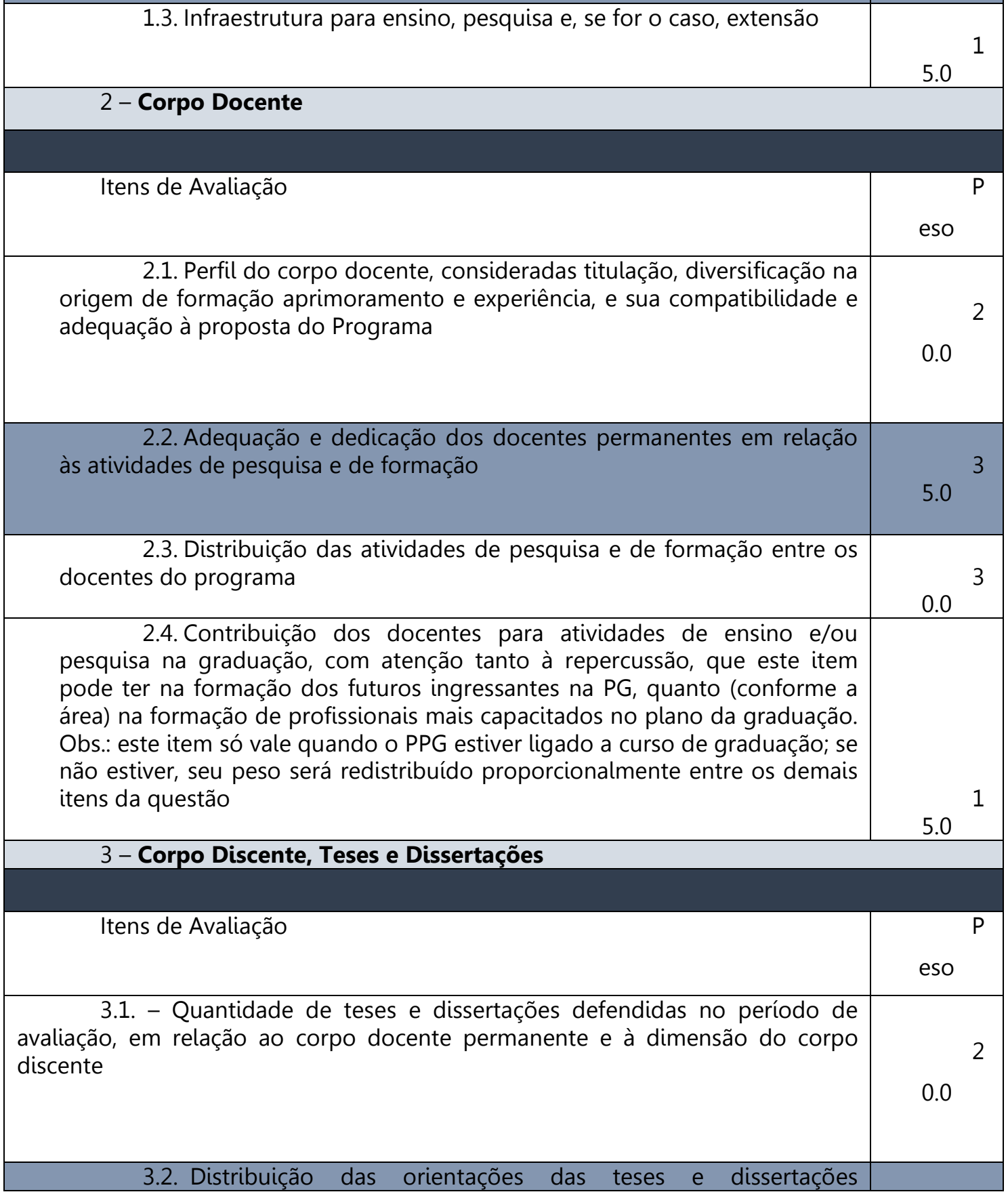




\section{revisto \\ Observatório}

ISSN n² $2447-4266$

Vol. 5, n. 3, Maio. 2019

DOI: http://dx.doi.org/10.20873/uft.2447-4266.2019v5n3p366

defendidas no período de avaliação em relação aos docentes do programa

3.3 Qualidade das teses e dissertações e da produção de discentes autores da pós-graduação e da graduação (no caso de IES com curso de graduação na área) na produção científica do programa, aferida por publicação e outros indicadores pertinentes a área.

3.4 Eficiência do programa na formação de mestres e doutores bolsistas: tempo de formação de mestre e doutores e percentual de bolsistas titulados

\section{4 - Produção Intelectual}

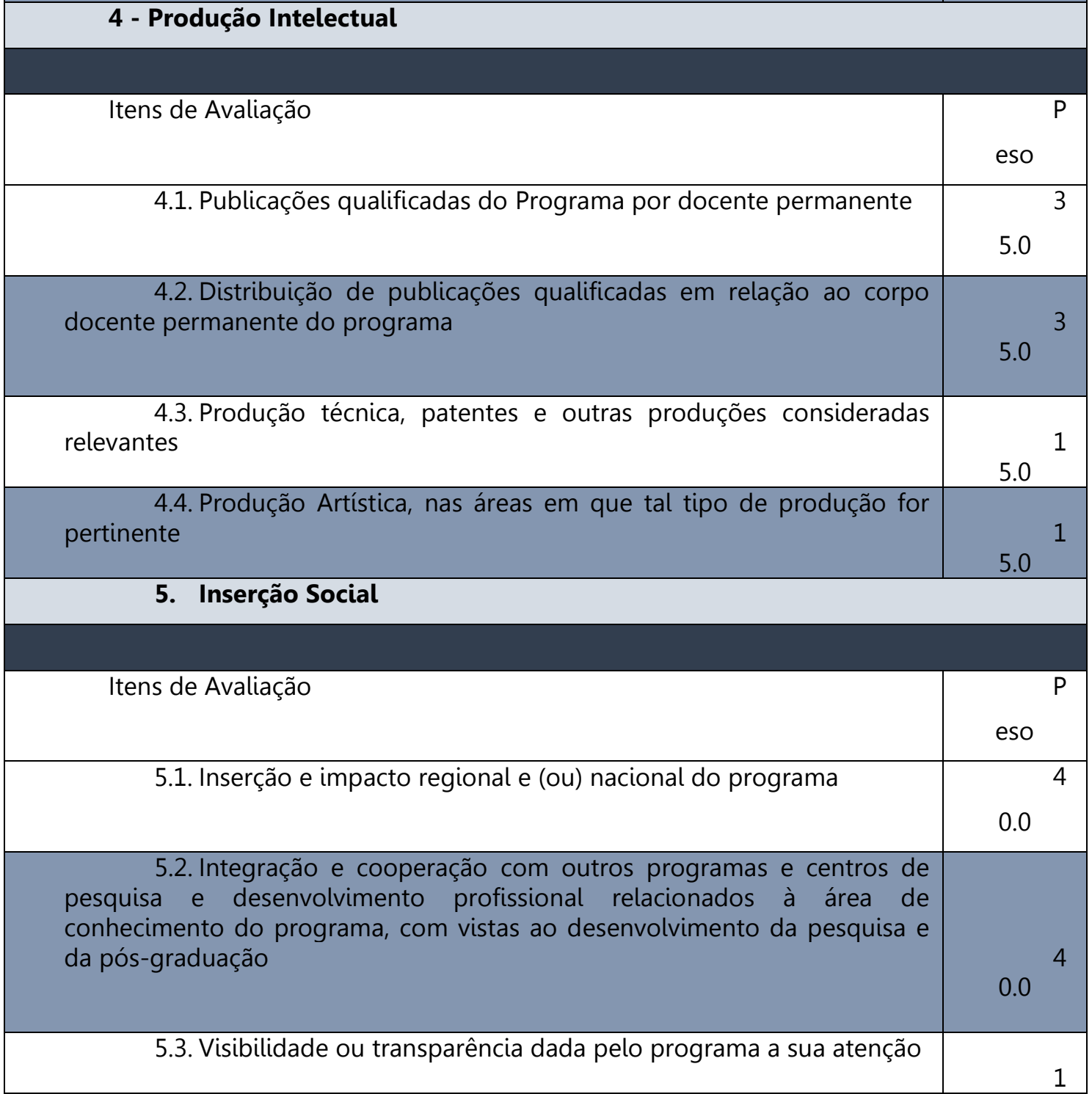




\section{Qrevisto \\ Qbservotório \\ ISSN n² 2447-4266 \\ Vol. 5, n. 3, Maio. 2019 \\ DOI: http://dx.doi.org/10.20873/uft.2447-4266.2019v5n3p366}

Fonte: Plataforma Sucupira / CAPES

A Avaliação foi criada pela CAPES com a intenção de acompanhar o desenvolvimento dos Programas após a aprovação e início das atividades, tendo como foco avaliar o cumprimento de todas as normativas inerentes ao funcionamento, atestando a qualidade, sugerindo melhorias e adaptações e, ainda, emitindo indicação de descredenciamento quando os programas não cumprem as normativas. Essas fichas avaliativas foram o ponto de partida para as análises dos programas, obtendo informações sobre como estão funcionando, quais os problemas encontrados pela comissão e as especificidades de cada um.

\section{Os Programas de mestrados e os resultados da Avaliação}

Analisando as três avaliações, depreendemos algumas constatações. No tocante à Proposta de Programa, as instituições estão quase equiparadas, duas receberam conceito "Regular" e uma o conceito "Bom". As justificativas da Comissão também têm similaridades. Os relatórios que serviram de base têm omissões que podem ter prejudicado o veredito final, omissões, por exemplo, de que existem professores em descompasso com o que é proposto e de que a infraestrutura é minimamente adequada para o funcionamento do Mestrado

Nas Universidades da região Norte, à princípio, há uma união de esforços dos docentes - com titulação necessária - para o mestrado funcionar. Mesmo sendo de áreas diferentes, eles buscam a união com a comunicação e assim contribuem para o processo de formação, entretanto, confirmam a escassez de docentes para atuar em programas que exigem titulação mais específica da área para compor núcleo. 


\section{Qrevisto \\ ISSN n² 2447-4266 \\ Vol. 5, n. 3, Maio. 2019 \\ DOI: http://dx.doi.org/10.20873/uft.2447-4266.2019v5n3p366}

No quesito "Docente", os programas repetem as similaridades: todos receberam conceito B. É comprovado que o capital intelectual é adequado, mas ficam evidentes que esses docentes não conseguem cumprir à risca os parâmetros da área e com isso nem todos conseguiram ministrar aulas durante o ano ou possuem orientandos, assim respondem adequadamente mas não plenamente aos requisitos.

De maneira imparcial, a Comissão avalia os dados enviados, mas não se debruça em entender, de fato, o ocorrido, pelo menos isso não é demonstrado nas Fichas de Avaliação. Com isso, quem a observa não vai saber se de fato o professor não orientou aluno ou se o aluno desistiu do professor, por exemplo. Como dito antes, o possível esforço dos docentes em fazer o programa existir e permanecer é levado em consideração e, mesmo quando se pede a reconsideração explicitando a real situação, a Comissão se sensibiliza, mas se limita a seguir o regramento nas tomadas de decisões, muitas vezes sentenciando a morte do programa e, também, do anseio da comunidade em dar andamento a formação superior.

Em "Corpo Discente, Teses e Dissertações", o programa implantado em 2016, o da UFT, recebeu conceito Não aplicável, provavelmente pelo pouco tempo de funcionamento e a impossibilidade do cumprimento dos requisitos exigidos, mas mesmo assim foi alertado sobre a falta de informações e da necessidade de todos docentes serem contemplados com orientandos, com o detalhe de que o regramento é exigido para o biênio mas, em relação ao docente, não foi especificado se a falta de orientando ocorreu em um ano ou em dois anos. Os outros dois programas receberam o mesmo conceito Bom, as diferenças dizem respeito a produção dos alunos, onde a UFAM teve média de $51,1 \%$ e foi classificada como "Bom". Já a UFPA obteve 92,5\%, considerado "Muito Bom". Sobre o tempo médio de titulação, os dois programas receberam 


\section{Qrevisto \\ Ooservatório \\ ISSN n² 2447-4266 \\ Vol. 5, n. 3, Maio. 2019 \\ DOI: http://dx.doi.org/10.20873/uft.2447-4266.2019v5n3p366}

"Muito bom", sendo que no PPGCOM da UFPA a média foi de 23,75 meses e o da UFAM 29,37 meses.

O quarto ponto da Avaliação, Produção Intelectual, apresentou um quadro complexo de entendimento. Se existe um ponto específico para avaliar o docente, por que não especificar esses quesitos? O mesmo é feito com os discentes, onde, para chegar aos resultados, se utilizam de dois índices, a saber, matemática e regramento, os quais deixam de lado o contexto atual. Vejamos o caso da UFT: se a avaliação foi feita um ano após o início, entende-se que os resultados não seriam tão significativos, poderia não ser dado conceito permanecendo apenas a indicação do observado e possíveis melhorias. Além disso, o regramento dá lugar às minuciosidades, a exemplo das publicações, que foram consideradas em número significativo, mas apontam como falha o fato de $39 \%$ das publicações terem sido em revistas da própria instituição e $56 \%$ das publicações terem sido de um mesmo docente. O regramento diz que, quando for publicado em revista do próprio programa/instituição, o artigo sofre deságio de um estrato e o periódico também pode ser prejudicado.

É sabido, também, que revistas científicas demoram em dar o aceite, isso posto, nos cursos com pouco tempo de implantado, poderiam ser utilizados outros critérios, como o comprovante de submissão, tal como ocorre com os alunos. De palpável, temos que os programas que estão melhor estruturados e com certo período de funcionamento, conseguem cumprir o determinado, como é o caso da UFPA, que conseguiu "Muito bom" tanto na distribuição de publicações qualificadas quanto em relação ao corpo docente permanente do Programa e em Produção técnica, patentes e outras produções consideradas relevantes. Ao passo que a UFAM, onde o programa existe a mais tempo, 20 anos, mas que não conseguiu se ajustar diante dos problemas estruturais e de 


\section{Qbevisto \\ ISSN n² 2447-4266 \\ Vol. 5, n. 3, Maio. 2019 \\ DOI: http://dx.doi.org/10.20873/uft.2447-4266.2019v5n3p366}

recursos humanos, recebeu conceito Fraco, e apesar de ter elementos que podiam mudar o cenário, não o fez em tempo determinado.

E fechando, o último ponto - Inserção Social - onde ficam determinadas as condições de cada programa, o programa da UFAM ficou como regular, dado que pesou a não localização do site pela comissão (quando pesquisado o site na internet foi verificado que e na data de 31/08/2018 pôde, porém o computador utilizado tem antivírus e aponta tal endereço eletrônico como muito frágil em questões de segurança e não recomenda o acesso). Como a intenção maior era a busca pelo Doutorado e, com isso, alavancar inserção no cenário da produção do conhecimento e formação de recursos humanos, a Comissão constatou a ausência da realização de eventos; a não realização de projetos como DINTER/MINTER e/ou cooperação acadêmica PROCAD e, ainda, investimentos insuficientes nas pesquisas de pós-graduação.

O PPGCOM da UFPA foi o melhor conceituado nesse ponto ("Muito Bom") os três quesitos foram avaliados positivamente demonstrando $O$ cumprimento do que foi solicitado. Já o da UFT, recebeu conceito "Bom", indicando que está trilhando o caminho correto.

Após se debruçar sobre os dados apresentados pela Avaliação Quadrienal, se fez necessário inferir algumas situações que podem contribuir com o quadro ora apresentado. Nunca fora novidade o clamor da região norte por mais atenção e investimentos para a educação superior. Emilio et al. (2014, p. 163) revelou, em seus estudos sobre a fixação dos recursos humanos na região Norte do país, que, apesar de deter mais de $60 \%$ do território Nacional, somente $4,8 \%$ dos cursos brasileiros de mestrado acadêmico, doutorado e mestrados profissionalizantes estão localizados nessa região, demonstrando o pequeno investimento proporcional. 


\section{Crevisto}

ISSN n² 2447-4266

Vol. 5, n. 3, Maio. 2019

DOI: http://dx.doi.org/10.20873/uft.2447-4266.2019v5n3p366

Em 2014, na 66 Reunião Anual da SBPC, em Rio Branco, no Acre, conforme mostrou o site da SBPC5, o debate "Amazônia: Desafios de formação e fixação de doutores" apresentou cenários das Instituições de Ensino da região, onde seus representantes lamentaram a falta de políticas claras de incentivo à formação superior, num país onde $70 \%$ dos brasileiros não possuíam sequer o ensino médio, e tal situação refletia principalmente na formação de professores. Os docentes também citaram a necessidade de criação de programas específicos para as áreas emergentes e mudança estrutural do que naquela época já existia. Por fim, destacaram que o quadro de mestres e doutores era bem reduzido, pois a região possuía o menor número de instituições federais de ensino e pesquisa, aliada a uma distribuição desigual de recursos que não permitia a formação e manutenção de um sistema de ciência e tecnologia equilibrado com fluxo de mestres e doutores e realização de pesquisas.

No ano seguinte, em 2015, segundo notícia publicada pelo site da UFAM6 sobre o XV Seminário Interdisciplinar de Pesquisa em Educação, a formação de mestres e doutores e a realização de pesquisas seria tema de debates. Docentes destacaram novamente a necessidade da fixação de docentes no Norte do país, pois através da titulação do doutorado existia a possibilidade da realização de pesquisas avançadas, sendo isso essencial às condições para autuação da pesquisa e a formação do próprio pesquisador. Indicou-se, também, a estruturação de Rede de Pesquisa, em conexões com outros centros de pesquisas do país, encurtando distâncias e proporcionando ao pesquisador compartilhamento e troca de experiências. Também já se

\footnotetext{
5 Citações referentes ao texto publicado no seguinte link: http://portal.sbpcnet.org.br/noticias/66a-reuniao-anualquebraamazonia-desafio-de-formacaoe-fixacao-de-doutores/ pesquisado em 28/08/2018.

$6 \quad$ https://ufam.edu.br/noticias-bloco-esquerdo/4717-pesquisa-e-fator-preponderante-parafixacao-de-doutores-na-amazonia-diz-professor-do-icsez-no-xv-seinpe pesquisado em $28 / 08 / 2018$
} 


\section{Qrevisto}

Vol. 5, n. 3, Maio. 2019

DOI: http://dx.doi.org/10.20873/uft.2447-4266.2019v5n3p366

sinalizava o fechamento de programas que por não conseguiram realizar todos os requisitos inerentes às exigências para o funcionamento deles.

Em outro momento, deputados, reitores e pró-reitores de pós-graduação e pesquisa de instituições do Norte do país, juntamente com representantes do Ministério de Ciência e Tecnologia, participaram de reunião na CAPES com o objetivo de definir formas de apoio institucional para o desenvolvimento da ciência e tecnologia na região amazônica. Conforme destaca o site do $\mathrm{MEC}^{7}$. O grupo tinha como meta a criação de 69 mestrados e 42 doutorados, sendo que, naquela época, na região Norte existiam 141 cursos de pós-graduação, 111 mestrados e 35 doutorados. Essa reunião teria ocorrido em 2007 conforme atesta o site da $\mathrm{CAPES}^{8}$ que replicou a matéria. Atualmente, segundo a CAPES, o quantitativo seria de 317 cursos de pós-graduação, sendo 189 mestrados, 81 doutorados e 47 mestrados profissional 9 .

Em 2017, o jornal a Folha de São Paulo ${ }^{10}$ houve, em Manaus, um seminário intitulado "O Futuro da Amazônia", nele foi realizada uma mesa de debates onde o foco foi a falta de cientistas doutores na Amazônia, sendo que tal ausência seria entrave para o crescimento e o desenvolvimento sustentável da região. O Coordenador do INPA - Instituto Nacional de Pesquisa da Amazônia - , naquele ano, Paulo Maurício de Alencastro Graça, destacou que toda a região Norte contava com menos de $11 \%$ do total de doutores existentes no Sudeste, se apoiando em dados da CAPES de 2016 que mostravam que o contingente local de pesquisadores doutores era de 7.713 e, no Sudeste, 67.514,

\footnotetext{
${ }^{7}$ http://portal.mec.gov.br/rede-de-educacao-para-a-diversidade/180-estudantes108009469/pos-graduacao-500454045/9111-sp-1572048734 pesquisado em 28/08/2018. 8 http://www.capes.gov.br/sala-de-imprensa/noticias/1906-blank-1721414 pesquisado em 28/08/2018.

${ }^{\text {https://sucupira.capes.gov.br/sucupira/public/consultas/coleta/programa/quantitativos/quantit }}$ ativoUf.jsf?cdRegiao=1 acessado em 28/08/2018.

${ }^{10}$ https://www1.folha.uol.com.br/seminariosfolha/2017/11/1938684-regiao-norte-tem-11-donumero-de-pesquisadores-doutores-do-sudeste.shtml acesso em 28/08/2018.
} 


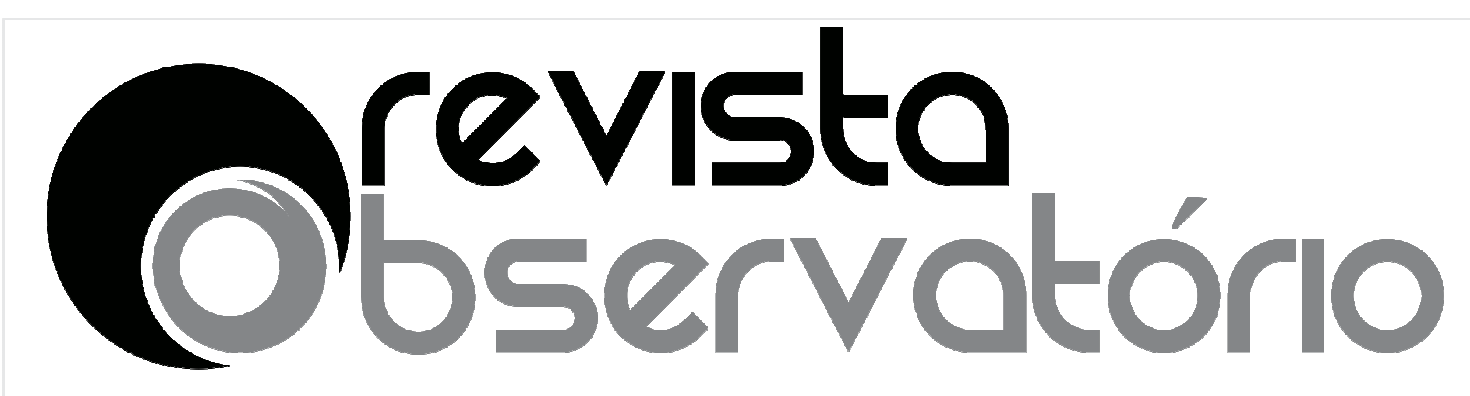

ISSN n² 2447-4266

Vol. 5, n. 3, Maio. 2019

DOI: http://dx.doi.org/10.20873/uft.2447-4266.2019v5n3p366

já em todo o Brasil eram 146.759. Completou revelando que a diferença no número de doutores classificados era de 14 frente aos 857 do Sudeste, ressaltando que esse público é justamente o que tem maior potencial para atrair financiamento.

O Reitor da UFAM, Sylvio Mário Puga Ferreira, ainda na mesma matéria, admitiu que existiam concursos, haviam aprovados, mas a estada era curta, porque muitos docentes aproveitavam o advento da transferência e iam para outros Estados. Os cursos novos são os mais atingidos por essas saídas e apontou a política de fixação, incentivo financeiro, parceria com Universidades estrangeiras, institutos de pesquisa e iniciativa privada, poderiam contornar os problemas de logística e falta de estrutura.

Oliveira (2013), em seus estudos sobre a pós-graduação na região Norte do Brasil, destacou o Fórum de Pró-Reitores de Pesquisa e Pós-graduação das Instituiç̧̃es de Ensino Superior da Região Norte ocorrido em Boa Vista-RR, em maio de 2011, apresentou um manifesto chamado de Carta de Boa Vista. O documento chamava atenção para as assimetrias regionais no desenvolvimento científico e tecnológico que ainda existiam mesmo com a existência de um grande esforço coletivo para modificar a realidade, a exemplo da criação de novas Universidades, da expansão de ofertas de novos cursos e vagas para ingresso discentes, da interiorização e evolução do número de docentes efetivos, conforme apresentam os dados coletados e apresentados pela CAPES: 


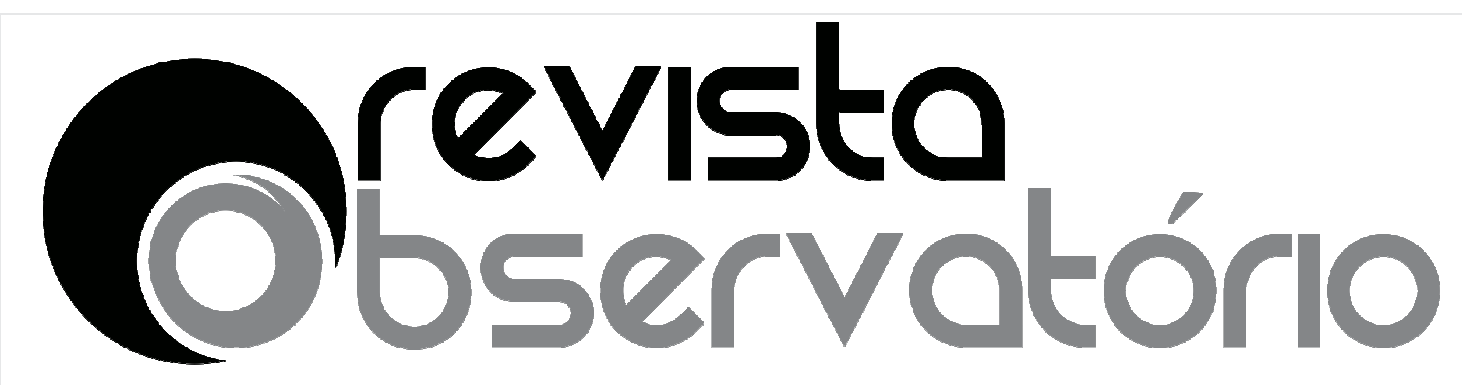

ISSN n² 2447-4266

Vol. 5, n. 3, Maio. 2019

DOI: http://dx.doi.org/10.20873/uft.2447-4266.2019v5n3p366

Figura 7: Evolução do Número de docentes efetivos de 2002 a 2012

\begin{tabular}{|c|c|c|c|c|c|c|c|c|c|c|c|}
\hline \multicolumn{12}{|c|}{$\begin{array}{l}\text { Evolução do Número de Docentes Efetivos das IFES, } \\
\text { por regiäo geográfica, entre } 2002 \text { e } 2012\end{array}$} \\
\hline Região & 2002 & 2003 & 2004 & 2005 & 2006 & 2007 & 2008 & 2009 & 2010 & 2011 & 2012 \\
\hline Sudeste & 14.714 & 14.226 & 14.302 & 14.428 & 15.703 & 15.776 & 16.436 & 18.836 & 21.350 & 22.256 & 22.256 \\
\hline Nordeste & 11.805 & 11.240 & 11.511 & 11.687 & 12.761 & 12.850 & 14.018 & 16.361 & 18.156 & 18.893 & 18.891 \\
\hline Sul & 8.100 & 7.687 & 7.708 & 7.815 & 8.249 & 8.339 & 8.715 & 9.515 & 10.792 & 11.489 & 11.497 \\
\hline C-Oeste & 4.246 & 4.083 & 4.108 & 4.233 & 4.742 & 4.698 & 5.228 & 6.243 & 6.982 & 7.251 & 7.257 \\
\hline Norte & 3.465 & 3.587 & 3.829 & 4.055 & 4.543 & 4.540 & 4.876 & 5.684 & 6.392 & 6.731 & 6.733 \\
\hline Total & 42.330 & 40.823 & 41.458 & 42.218 & 45.998 & 46.203 & 49.273 & 56.639 & 63.672 & 66.620 & 66.634 \\
\hline
\end{tabular}

Fonte: Oliveira (2014, p. 23) 


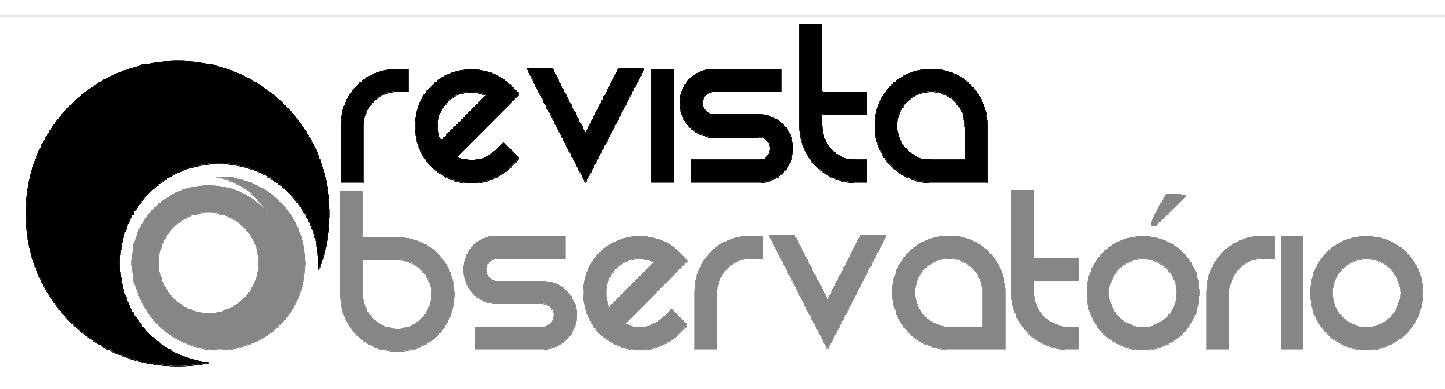

ISSN n² 2447-4266

Vol. 5, n. 3, Maio. 2019

DOI: http://dx.doi.org/10.20873/uft.2447-4266.2019v5n3p366

Figura 8: Evolução do número de docentes efetivos da região Norte de 2002 a 2012

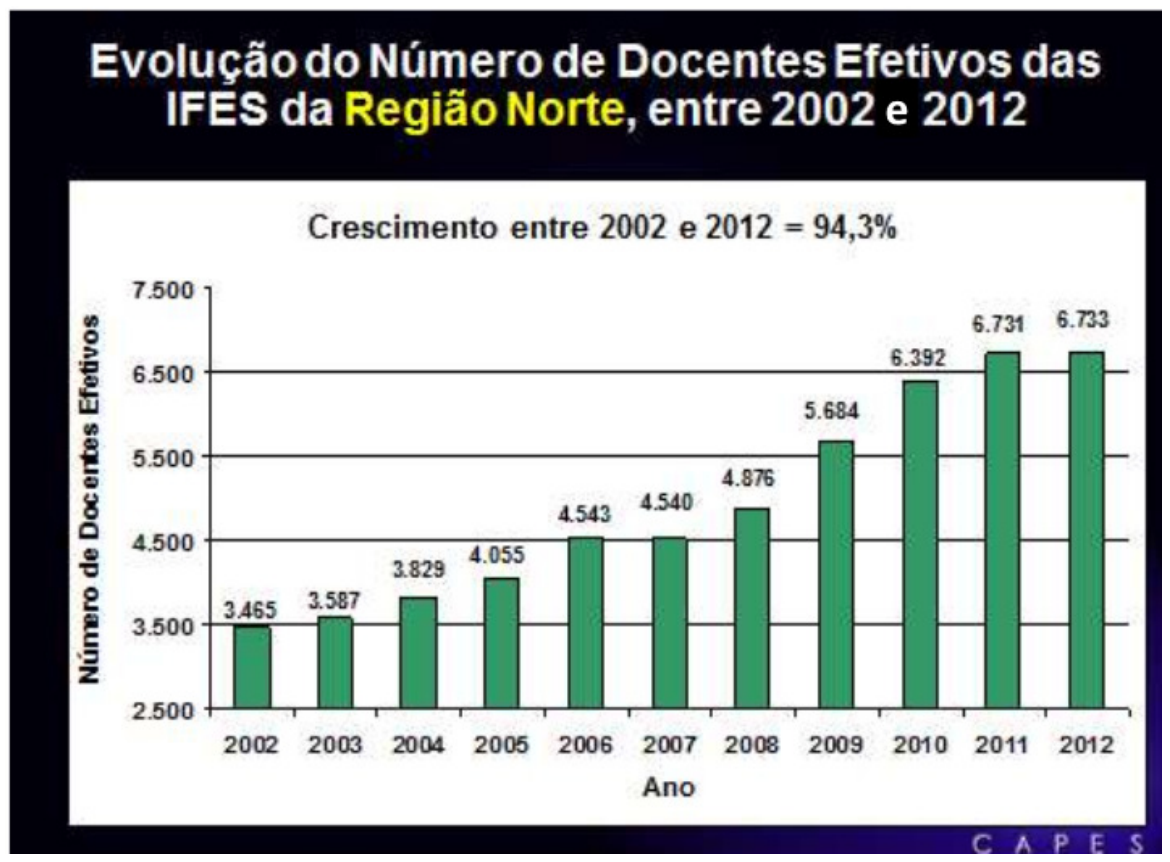

Fonte: Oliveira (2014, p.23)

Essas dificuldades apontadas, o pequeno volume de investimentos destinados aos fomentos de pesquisa e bolsas da CAPES - 5\% - e, ainda, a diversidade de formação dos docentes que faziam parte do programa, devem ter contribuído com o quadro de distância entre a proposta do programa e os projetos realizados, algo que pode ter ocorrido devido à dificuldade em adequar áreas diversas com a Comunicação. No caso da UFAM, especificamente, outro ponto que pode ter colaborado com o resultado negativo é que, possivelmente, para formar o programa, a opção foi juntar docentes de outras áreas que não da comunicação, com isso acabaram pecando no alinhamento entre proposta do programa e a prática. Hipótese que foi corroborada por Oliveira (2014), quando este aponta como sendo um problema na região norte, o número elevado de docentes que não possui título de 


\section{Qrevisto \\ Qbervatório \\ ISSN n² 2447-4266 \\ Vol. 5, n. 3, Maio. 2019 \\ DOI: http://dx.doi.org/10.20873/uft.2447-4266.2019v5n3p366}

doutor, o que é ocasionado pela falta de políticas eficazes para recrutar candidatos titulados às vagas abertas por meio de concursos públicos, assim como pelo pouco incentivo e valorização da qualificação. A autora acrescentou, ainda, ser fundamental a oferta de número maior de doutorados interinstitucionais, concessão de bolsas de pelo menos três anos para aqueles cuja qualificação seja externa, sugerindo o fim do impedimento legal de qualificação docente durante o estágio probatório, tudo isso com vias a se diminuir as assimetrias regionais.

\section{Considerações Finais}

Neste estudo buscamos verificar como ocorria o processo de formação dos docentes que, num futuro próximo, estarão nos cursos de graduação conduzindo discentes no caminho da formação. A inquietação era em saber como estavam estruturados esses programas e assim perceber se a prática e as transformações contemporâneas eram ou não contempladas durante a jornada do mestrado.

O que fica evidenciado nas Fichas de Avaliação e sites dos Programas é a preocupação em atender aos requisitos básicos delimitados pela CAPES e qualquer inovação poderia ser vista como algo ousado que pode significar rebaixamento de conceitos ou mesmo descredenciamento. Os programas são claramente voltados para a formação de pesquisadores, perceptível pela oferta de disciplinas mais ligadas as ciências sociais e mesmo pela formação de docentes responsáveis em preparar profissionais para um mundo em constantes atualizações e exigências diversas que resolvem não focar na educação continuada. Temos, ainda, o cenário de sucateamento das Universidades onde os recursos são pequenos e os problemas enormes, as instituições focam em melhorar as deficiências que possuem para se manter na 


\section{Qrevisto \\ Qbservatório \\ ISSN n² 2447-4266 \\ Vol. 5, n. 3, Maio. 2019 \\ DOI: http://dx.doi.org/10.20873/uft.2447-4266.2019v5n3p366}

corda bamba dos autorizados e em funcionamento, tendo que conviver com diferenciações, distâncias, dificuldades e contar com o desprendimento e empenho de docentes para a sobrevivência. Este estudo só confirmou que, em comparação as outras regiões, o Norte ainda carece de muito mais investimentos, sendo que a área de comunicação tem a menor concentração de cursos e programas, forçando assim a migração para a qualificação na referida área.

Finalizar essa pesquisa não foi somente cumprir com as formalidades educacionais, foi além da inquietude inicial: foi perceber a real responsabilidade de um aluno frente a um programa de mestrado, assim como a do professor. Os desvios de um ou outro não são particularidades e sim o coletivo, pois qualquer descompasso afeta diretamente o todo. Nesse processo, docentes e discentes devem vestir a "capa" da invencibilidade e juntos colaborar na construção do caminho rumo a excelência. Por outro, lado é perceptível que a comunicação é a principal barreira a ser transposta. Em todas as avaliações os apontamentos circundam o fato de não ficar evidenciado este ou aquele detalhe. Uma ironia, tendo em vista que todos os programas são da área da comunicação e deveriam praticar bem essa atividade.

Por fim, o desejo é que o presente estudo possa contribuir para um olhar mais apurado sobre os processos e políticas de formação nas universidades da região Norte, que sofrem, há muito tempo, com a falta de investimentos que visem dirimir as discrepâncias frente às outras IES de outras regiões brasileiras (GADINI, 2018; COLFERAI, 2019). Contribuir, ainda, para despertar nos gestores e integrantes dos programas a necessidade urgente de olhar a formação para além da Universidade, pois o que adianta formar pesquisadores e docentes que não terão onde se inserir mediante a diminuição significativa dos postos no serviço público e a precarização da atividade docente. Que a pesquisa sirva, 


\section{Crevisto}

ISSN n² 2447-4266

Vol. 5, n. 3, Maio. 2019

DOI: http://dx.doi.org/10.20873/uft.2447-4266.2019v5n3p366

também, de consulta para os colegas jornalistas e ou interessados em ingressar em programa de mestrados e para o melhor entendimento sobre a forma de educação continuada e o papel de cada um no processo educacional.

\section{Referências}

BALBACHEVSK, Elizabeth. A pós-graduação no Brasil: novos desafios para uma política bem sucedida. Universidade Federal de Goiás, 2004. Disponível em: https://portais.ufg.br/up/67/o/Pos-Graduacao Brasil 2.pdf. Acesso em 29/09/2017.

BAUMAN, Zygmunt. Modernidade líquida. Rio de Janeiro: Jorge Zahar, 2001.

BRASIL. Conselho Federal de Educação. (1965). Parecer no 977/65. Definição dos cursos de pós-graduação. Brasília, DF, 1965. Disponível em: https://capes.gov.br/images/stories/download/avaliacao/avaliacao-n/Parecer977-1965.pdf. Acesso em: 29 set. 2017.

CAPES. 2017. Disponível em: http://www.capes.gov.br/historia-e-missao. Acesso em 13 de nov. 2017.

CASTELLS, Manuel. $\boldsymbol{A}$ sociedade em rede (A era da informação: economia, sociedade e cultura); Volume 1, São Paulo: Editora Paz e Terra, 2a.Ed., 1999.

CELLARD, A. A análise documental. In: POUPART, J. et al. A pesquisa qualitativa: enfoques epistemológicos e metodológicos. Petrópolis, Vozes, 2008.

COLFERAI, S. Pesquisa na amazônia: notas históricas para a produção de conhecimento comunicacional. Revista Observatório, v. 5, n. 2, p. 153-173, 1 abr. 2019. DOI: https://doi.org/10.20873/uft.2447-4266.2019v5n2p153.

CÓRDOVA, Rogério de Andrade. CAPES: origem, realizações, significações. vol. I. Brasília: CAPES, 2003.

GADINI, S. Mídia e cultura regional nas pesquisas em jornalismo: Um retrato da tematização e análise do agendamento cultural nos estudos realizados na UEPG 


\section{Crevisto}

ISSN n² 2447-4266

Vol. 5, n. 3, Maio. 2019

DOI: http://dx.doi.org/10.20873/uft.2447-4266.2019v5n3p366

entre 2010 e 2015. Revista Observatório, v. 4, n. 5, p. 413-433, 1 ago. 2018. DOI: https://doi.org/10.20873/uft.2447-4266.2018v4n5p413.

GUIMARÃES, Jorge A. O modelo brasileiro de formação de cientistas. 2008. 93 diapositivos(slides), color. (XXIV Encontro Nacional de Pró-Reitores de Pesquisa e Pós-graduação). Universidade Federal de Ouro Preto, Minas Gerais, 2008.

LIMA, Claudia do Carmo Nonato. Comunicação e mundo do trabalho do jornalista: o perfil dos jornalistas de São Paulo a partir da reconfiguração dos processos produtivos da informação. 2010. Dissertação (Mestrado em Teoria e Pesquisa em Comunicação) - Escola de Comunicações e Artes, Universidade de São Paulo, São Paulo, 2010. doi:10.11606/D.27.2010.tde-30112010-160410. Acesso em: 04 de fev. 2018.

LIMA, Licínio C.; AZEVEDO, Mário Luiz Neves de; CATANI, Afrânio Mendes. o processo de Bolonha, a avaliação da educação superior e algumas considerações sobre a Universidade Nova. Avaliação (Campinas), Sorocaba, v.13, n.1, p.7-

36, mar. 2008.Disponível:http://www.scielo.br/scielo.php?script=sci_arttext\&pid $=$ S1414-40772008000100002\&lng =pt\&nrm=iso $>$. Acesso em: 08 nov. 2016.

LIMA JÚNIOR, W, \& de OLIVEIRA, A. (2015). Habilidades tecnológicas e ensino superior em jornalismo no Brasil: observação das exigências contemporâneas e seu contraste com as grades curriculares. E-Compós, 18(2). Acesso em: 26 de ago. 2018.

MELO, Ana Souto e. Enquadramento Histórico legal do processo de Bolonha e o seu impacto no sistema de ensino superior português. Revista Observatório, Palmas, v. 3, n. 6, p. 75-141, out. 2017. ISSN 2447-4266. Disponível em:https://sistemas.uft.edu.br/periodicos/index.php/observatorio/article/view/4 239 >. Acesso em: 30 jan. 2018.

PÔRTO JR., Gilson; SOUSA, Poliana Macedo de (Orgs.). Universidade(s) no Brasil: estudos e olhares. [recurso eletrônico] / Gilson Pôrto Jr.; Poliana Macedo de Sousa (Orgs.) - Porto Alegre, RS: Editora Fi, 2016.

PÔRTO JUNIOR, Francisco Gilson Rebouças. Sobre os processos formativos, Bolonha e o curso de Comunicação Social/Jornalismo: consolidando-se 


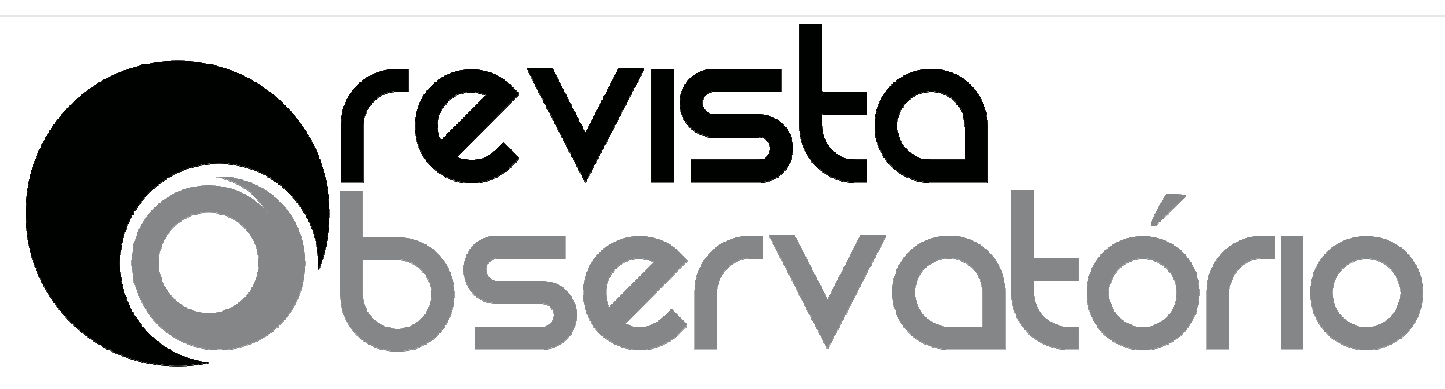

ISSN n² 2447-4266

Vol. 5, n. 3, Maio. 2019

DOI: http://dx.doi.org/10.20873/uft.2447-4266.2019v5n3p366

posições nas políticas educacionais. Revista Eletrônica Mutações, [S.L.], v. 6, n. 10, p. 13-24, mar. 2015. ISSN 2178-7018. Disponível em: <http://www.periodicos.ufam.edu.br/relem/article/view/799>. Acesso em: 30 ago. 2018.

PÔRTO JUNIOR, Francisco Gilson Rebouças. A Universidade do Distrito Federal (UDF): Um Retrospecto. In: Gilson Pôrto Jr.. (Org.). Anísio Teixeira e o Ensino Superior. Brasília: Bárbara Bela, 2001, v. 1, p. 179-204.

SANTOS, Ana Lúcia Felix dos \& AZEVEDO, Janete Maria Lins de. A pósgraduação no Brasil, a pesquisa em educação e os estudos sobre a política educacional: os contornos da constituição de um campo acadêmico. In: Revista Brasileira de Educação, v. 14 n. 42 set./dez. 2009. Disponível em: http://www.scielo.br/pdf/rbedu/v14n42/v14n42a10.pdf. Acesso em: 07 de out. de 2017.

SANTOS, Cássio Miranda dos. Tradições e contradições da pós-graduação no Brasil. 2003. Disponível em: <http://www.scielo.br/pdf/es/v24n83/a16v2483.pdf>. Acesso em: 29 set. 2017.

SAVIANI, Demerval. O legado educacional do Regime Militar. Cadernos Cedes. Campinas, SP, vol.28, n.76, set./dez.2008.

SILVA, Luciana Leandro da. A formação de formadores no contexto da transnacionalização educativa: reflexões a partir da aplicação do processo de Bolonha em Espanha e Portugal. Educ. Soc., Campinas, v. 34, n. 122, p. 247-263, Mar.2013. Disponível em: http:www.scielo.br/scielo.php?script=sci_arttext\&pid=S0101-

$73302013000100014 \&$ lng =en\&nrm=iso >. access on 30 Jan 2018.

VELLOSO, Jacques. A pós-graduação no Brasil: formação e trabalho de mestres e doutores no país. Cad. Pesqui., São Paulo, v.34, n.122, p. 517, ago. 2004. Disponível em: http://dx.doi.org/10.1590/S010015742004000200012. Acesso em 07 out. 2017. 